OPEN ACCESS

Edited by:

Antonio Lupini,

Mediterranea University of Reggio

Calabria, Italy

Reviewed by:

Sheliang Wang,

Huazhong Agricultural University,

China

Bipin Kumar Pandey,

University of Nottingham,

United Kingdom

*Correspondence:

Xuexian $\mathrm{L}$

steve@cau.edu.cn

Specialty section:

This article was submitted to

Plant Nutrition,

a section of the journal

Frontiers in Plant Science

Received: 26 October 2021

Accepted: 06 December 2021

Published: 23 December 2021

Citation:

Ishfaq $M$, Zhong $Y$, Wang $Y$ and

Li X (2021) Magnesium Limitation

Leads to Transcriptional Down-Tuning

of Auxin Synthesis, Transport,

and Signaling in the Tomato Root.

Front. Plant Sci. 12:802399.

doi: 10.3389/fp/s.2021.802399

\section{Magnesium Limitation Leads to Transcriptional Down-Tuning of Auxin Synthesis, Transport, and Signaling in the Tomato Root}

\author{
Muhammad Ishfaq ${ }^{1}$, Yanting Zhong ${ }^{1,2}$, Yongqi Wang ${ }^{1}$ and Xuexian $\mathrm{Li}^{1 *}$ \\ ${ }^{1}$ College of Resources and Environmental Sciences, National Academy of Agriculture Green Development, Key Laboratory \\ of Plant-Soil Interactions, Ministry of Education, China Agricultural University, Beijing, China, ${ }^{2}$ Department of Vegetable \\ Sciences, China Agricultural University, Beijing, China
}

Magnesium (Mg) deficiency is becoming a widespread limiting factor for crop production. How crops adapt to $\mathrm{Mg}$ limitation remains largely unclear at the molecular level. Using hydroponic-cultured tomato seedlings, we found that total $\mathrm{Mg}^{2+}$ content significantly decreased by $\sim 80 \%$ under $\mathrm{Mg}$ limitation while $\mathrm{K}^{+}$and $\mathrm{Ca}^{2+}$ concentrations increased. Phylogenetic analysis suggested that Mg transporters (MRS2/MGTs) constitute a previously uncharacterized 3-clade tree in planta with two rounds of asymmetric duplications, providing evolutionary evidence for further molecular investigation. In adaptation to internal Mg deficiency, the expression of six representative MGTs (two in the shoot and four in the root) was up-regulated in Mg-deficient plants. Contradictory to the transcriptional elevation of most of MGTs, Mg limitation resulted in the $\sim 50 \%$ smaller root system. Auxin concentrations particularly decreased by $\sim 23 \%$ in the Mg-deficient root, despite the enhanced accumulation of gibberellin, cytokinin, and ABA. In accordance with such auxin reduction was overall transcriptional downregulation of thirteen genes controlling auxin biosynthesis (TAR/YUCs), transport (LAXs, $P I N s)$, and signaling (IAAs, ARFs). Together, systemic down-tuning of gene expression in the auxin signaling pathway under Mg limitation preconditions a smaller tomato root system, expectedly stimulating MGT transcription for Mg uptake or translocation.

Keywords: magnesium limitation, MRS2/MGT gene family, auxin, auxin signaling, PIN family, root system

\section{INTRODUCTION}

Magnesium (Mg), a non-substitutive component, performs a vast array of physiological and biochemical functions in plants. The well-addressed function of $\mathrm{Mg}$ is its participation in photosynthetic $\mathrm{CO}_{2}$ assimilation (Gerendás and Führs, 2013; Li J. et al., 2020). A large proportion (15-35\%) of total available $\mathrm{Mg}$ within a plant is confined to the light-capturing complex of chloroplasts, where it not only functions as a structural element of chlorophyll (Chl) but also underpins photosynthetic performance (Farhat et al., 2016; Chen et al., 2018). Mg also acts as 
a cofactor of various enzymes ( $>300$ ) involved in essential biological processes such as Chl biosynthesis, sugar transportation, and energy metabolism (Ma et al., 2016; Chen et al., 2018; Koch et al., 2019). Recent meta-analysis-based studies highlighted that $\mathrm{Mg}$ deficiency is becoming a rising concern in most production systems due to the large removal of $\mathrm{Mg}$ in intensive crop production systems and injudicious fertilization (Hauer-Jákli and Tränkner, 2019; Wang et al., 2020).

Plant roots employ adaptive mechanisms in response to environmental stimuli or nutrient variations. For instance, mild nitrogen or phosphate deficiency tends to enhance root growth for a greater nutrient absorption or translocation system (Ahmad et al., 2018; Meier et al., 2020; Nadeem et al., 2020). However, how roots respond to the $\mathrm{Mg}$ deficiency stress is inconsistent: root growth is clearly reduced by $\mathrm{Mg}$ deficiency in bean plants (Vicia faba L.) (Neuhaus et al., 2014), Arabidopsis thaliana (Gruber et al., 2013; Li D. et al., 2020), and potato (Solanum tuberosum L.) (Koch et al., 2019, 2020). However, in other studies, Mg deficiency does not considerably affect root growth in Arabidopsis (Hermans and Verbruggen, 2005) and Chinese cabbage (Verbruggen and Hermans, 2013). Notably, low Mg supply leads to more root hair development in Arabidopsis as an adapted strategy (Niu et al., 2014; Liu M. et al., 2018). Hence, further study is required to unravel root adaptation to $\mathrm{Mg}$ deficiency stress at morphological and molecular levels in different plant species, especially in model crop plants.

$\mathrm{Mg}$ transporter genes, homologues of CorA Mg transporters, have been identified across crop plants and classified into the CorA/MRS2/MGT family (Chen et al., 2018; Yan et al., 2018; Zhang et al., 2019a). MRS2/MGT genes are supposed to be primary transporters for $\mathrm{Mg}^{2+}$ uptake, distribution, and homeostasis in plants (Li et al., 2001, 2016; Marschner, 2012; Saito et al., 2013). In Arabidopsis, the MRS2/MGT gene family is composed of ten members, and several genes are important for $\mathrm{Mg}^{2+}$ uptake and transportation under normal or $\mathrm{Mg}$ limitation (Oda et al., 2016; Yan et al., 2018). However, the activity of these MGTs relies on the genetic makeup of plant species (Cui et al., 2016). Mg deficiency alters MRS2/MGT expression in the rice root (Chen et al., 2017; Zhang et al., 2019b); however, moderate $\mathrm{Mg}$ deficiency had no impact on MRS2/MGT transcription in the Arabidopsis root (Hermans et al., 2010; Ogura et al., 2018). Therefore, further molecular investigation is needed to understand the evolutionary dynamics, and transcription patterns of these MRS2/MGT family transporters in plant roots under $\mathrm{Mg}$ limitation.

Auxin is a key player regulating root growth and development (Porco et al., 2016; Stoeckle et al., 2018; Meier et al., 2020; Moret et al., 2020; Hu et al., 2021). During auxin biosynthesis, TRYPTOPHAN AMINOTRANSFERASE OF ARABIDOPSIS/TRYPTOPHAN AMINOTRANSFERASERELATED (TAA/TAR) controls indole-3-pyruvic acid (IPA) generation and YUCCA (YUC) acts to convert IPA into Indole3-acetic acid (IAA) (Mashiguchi et al., 2011; Song et al., 2017). Auxin then moves across membranes by AUXIN1/LIKE-AUX1 (AUX1/LAX) influx carriers, PIN-FORMED (PIN) efflux carrier, PIN-LIKES (PILS), or ATP-binding cassette subfamily B (ABCB)-type transporters (Sauer and Kleine-Vehn, 2019;
Vosolsobe et al., 2020). PIN transporters largely control intercellular and intracellular auxin transport (Zhang $\mathrm{Y}$. et al., 2020); LAX3 acts as an auxin influx carrier during root development (Maghiaoui et al., 2020). Finally, AUXIN RESPONSE FACTORS (ARFs) together with AUXIN/INDOLE ACETIC ACID (Aux/IAA) regulate downstream gene expression in the auxin signaling pathway (Roosjen et al., 2018). Under low availability of IAA, Aux/IAA proteins bind to AUXIN RESPONSE FACTORS (ARFs) to prevent their expression (Lavenus et al., 2013; Mironova et al., 2017); while higher levels of IAA promotes Aux/IAA degradation to release the suppression of auxin-responsive genes (Wang and Estelle, 2014; Weijers and Wagner, 2016). Such Aux/IAA degradation is strongly linked with lateral root development (Guseman et al., 2015).

Auxin biosynthesis, transport, and signaling are essential components related to root growth and root system architecture. Nutrient deficiency stresses frequently enhance auxin accumulation in roots. For instance, low levels of nitrate stimulate auxin accumulation in roots of Arabidopsis and maize (Ma et al., 2014; Sun et al., 2020), and low concentrations of ammonium also increase auxin content in the Arabidopsis root (Meier et al., 2020). Similarly, phosphorus deficiency improves auxin levels in roots of Arabidopsis and Foxtail millet (Ahmad et al., 2018; Bhosale et al., 2018), and potassium limitation modulates the expression of auxin-responsive genes in the root of rice (Ma et al., 2012). Zinc supply alters auxin homeostasis in the roots of Arabidopsis (Zhang et al., 2018; Wang et al., 2021). Few studies show the distribution and transcriptional variations of auxin in response to $\mathrm{Mg}$ supply. For instance, $\mathrm{P}$ and $\mathrm{Mg}$ interactively affect the redistribution and accumulation of auxin in Arabidopsis roots through altered signaling functions of AUX1, PIN2, and PIN3, which modulate primary root elongation and growth direction (Niu et al., 2015). In another study, optimum Mg supply promotes PIN2-based polar auxin transport and distribution under aluminum toxicity, which restores root growth by regulating root surface $\mathrm{pH}$ (Zhang Z. et al., 2020). Transcriptomic data show that $\mathrm{Mg}$ deficiency differentially regulates expression of auxin-responsive genes in Arabidopsis and Citrus sinensis (Hermans et al., 2010; Yang et al., 2019). For instance, Mg deficiency altered expression of auxin efflux carrier proteins and AUX/IAA (IAA1, IAA5, IAA6, IAA14, IAA17, IAA19) in the leaves of Arabidopsis (Hermans et al., 2010). Similarly, under Mg deficiency, IAA11, IAA13, IAA29, and ARF4 are upregulated by 2-, 1. 5-, 2. 8-, and 2.5-fold, respectively, in the leaves of Citrus sinensis (Yang et al., 2019). However, how Mg limitation affects auxin homeostasis and related gene expression in plant roots remains elusive.

Tomato (Solanum lycopersicum L.) is one of the most important vegetable plants worldwide and it requires more $\mathrm{Mg}$ to form the same biomass than grass or grain crops (Broadley and White, 2010; Gerendás and Führs, 2013). In this study, we used tomato as a model plant to investigate the response of seedlings, especially the root system, to low external $\mathrm{Mg}$ supply at the molecular level. We performed the evolutionary analysis of the MRS2/MGT-type $\mathrm{Mg}$ transporter family for 
further molecular investigation. We found overall up-regulation of $\mathrm{Mg}$ transporters in the smaller root and consistent downregulation of auxin accumulation and related gene expression in the root under $\mathrm{Mg}$ limitation.

\section{MATERIALS AND METHODS}

\section{Plant Growth Conditions and Experimental Set-Up}

This study was conducted in a standard greenhouse at China Agricultural University, Beijing, China. The greenhouse environment was as follows: $28 / 22^{\circ} \mathrm{C}$ temperature, $60 \%$ relative humidity, 14/10 light/dark photoperiod, and natural daylight. Tomato (Solanum lycopersicum L.) cv. Xianliang, procured from Dalian Lida Seed Company (China), was used as the plant material in this study. Seeds were first surfacesterilized by heating in a water bath at $55^{\circ} \mathrm{C}$ for $15 \mathrm{~min}$, and soaking in $10 \% \mathrm{Na}_{3} \mathrm{PO}_{2}$ for $20 \mathrm{~min}$. Seeds were then nurtured by imbibing in distilled water (DW) for $6 \mathrm{~h}$, and germinated on moist filter paper covered with black plastic wrap in a growth chamber. The sprouted seeds with a $2-\mathrm{cm}$ primary root were sown in 50-cell seedling plug trays filled with commercially available potting soil containing low indigenous $\mathrm{Mg}\left(46 \mathrm{mg} \mathrm{kg}^{-1}\right)$, and were irrigated regularly with DW.

At the four fully unfolded compound leaf stage ( $\sim 23$-days after sowing), consistent and uniformly sized seedlings were transferred into continuously aerated 10-L (in $28 \times 25 \times 17 \mathrm{~cm}$ pots) nutrient solution. Nutrient solution composition was slightly modified from a published protocol for tomato culture (Cámara-Zapata et al., 2019). The final nutrient solution contained macro- and micronutrients as follows: $4 \mathrm{mM}$

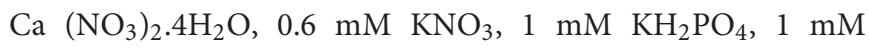
$\mathrm{MgSO}_{4} .7 \mathrm{H}_{2} \mathrm{O}, 90 \mu \mathrm{M} \mathrm{Na} 2 \mathrm{Fe}-\mathrm{EDTA}, 25 \mu \mathrm{M} \mathrm{H} \mathrm{BO}_{3}, 2 \mu \mathrm{M}$ $\mathrm{MnSO}_{4} \cdot \mathrm{H}_{2} \mathrm{O}, 2 \mu \mathrm{M} \mathrm{ZnSO}_{4} .7 \mathrm{H}_{2} \mathrm{O}, 0.5 \mu \mathrm{M} \mathrm{CuSO}{ }_{4} .5 \mathrm{H}_{2} \mathrm{O}$, and $0.5 \mu \mathrm{M}\left(\mathrm{NH}_{4}\right)_{6} \mathrm{Mo}_{7} \mathrm{O}_{24} \cdot 4 \mathrm{H}_{2} \mathrm{O}$. The experiment contained two levels of $\mathrm{Mg}$, one control (Ctrl) having optimum $\mathrm{Mg}$ as $1 \mathrm{mM} \mathrm{MgSO} 4.7 \mathrm{H}_{2} \mathrm{O}$, and another low $\mathrm{Mg}$ (LMG) consisting of $0.02 \mathrm{mM} \mathrm{MgSO} 4.7 \mathrm{H}_{2} \mathrm{O}$. The LMG level was determined according to our preliminary phenotypic screen by growing tomato seedlings at varying $\mathrm{Mg}$ concentrations $(0.02,0.06$, $0.25,1,4 \mathrm{mM})$. The onset of the treatment was established at the time of transplanting with the intention to avoid $\mathrm{Mg}$ accumulation in the vacuole at the very initial growth stages (Hauer-Jákli and Tränkner, 2019). In the base solution, $\mathrm{MgSO}_{4}$ was the only source of $\mathrm{SO}_{4}{ }^{2-}$, meanwhile, equivalent moles of $\mathrm{Na}_{2} \mathrm{SO}_{4}$ was applied to $\mathrm{Mg}$-depleted plants to maintain the relatively constant cation/anion balance and compensate the $\mathrm{SO}_{4}{ }^{2-}$ deficiency.

To avoid osmotic shock, seedlings were first grown in the $50 \%$-strength nutrient solution for 3 days, and then full-strength nutrient solution was supplied till harvest. This study was performed with six biological replicates and each biological replicate had six plants (technical replicates). The nutrient solution was replaced at an interval of 3 days to avoid ion depletion. The $\mathrm{pH}$ was maintained at 6.0 with $1 \mathrm{M}$ TRIS
$\left(\mathrm{C}_{4} \mathrm{H}_{11} \mathrm{NO}_{3}\right)$. After a 3-week treatment, seedlings were dissected at the root-shoot junction, flash-frozen in liquid- $\mathrm{N}_{2}$, and stored at $-80^{\circ} \mathrm{C}$ for physiological and molecular analysis. For root growth analysis, 2-week samples were also harvested. The experiment was reproduced at least two times.

\section{Elemental Analysis and Root-to-Shoot Translocation of $\mathbf{M g}^{2+}$}

For elemental analysis $\left(\mathrm{Mg}^{2+}, \mathrm{K}^{+}, \mathrm{Ca}^{2+}\right.$, and $\left.\mathrm{Na}^{+}\right)$in the plant material, oven-dried root and shoot samples were grounded separately by an electric grinder. The $100 \mathrm{mg}$ of tissue powder was weighed using a high-accuracy balance, and transferred in a Teflon digestion tube. Followed by, $6 \mathrm{ml}$ concentrated $\mathrm{HNO}_{3}$ was added and stood overnight until the vigorous reaction phase was over. Then, $2 \mathrm{ml} \mathrm{H}_{2} \mathrm{O}_{2}$ was added and digested in the microwave digestion system (MARS 6, CEM Microwave Technology LTD, United States). The digested solution was transferred into a $25-\mathrm{ml}$ volumetric flask and filled up to the calibration mark with ultrapure water. The concentrations of minerals in the solution were determined by an inductively coupled plasma-optical emission spectrometer (OPTIMA 3300 DV, Perkin-Elmer, MA, United States). After every 20 samples, the blank sample was included to ensure the accuracy of measurements. At least two sets of samples were run with six replicates, and concentrations of each element were quantified as described in our earlier study (Ishfaq et al., 2021). The total $\mathrm{Mg}^{2+}$ content and root-toshoot translocation of $\mathrm{Mg}^{2+}$ were successively quantified as follow: Total $\mathrm{Mg}^{2+}$ content $=[($ root dry biomass $\times$ root $\mathrm{Mg}^{2+}$ concentration) + (shoot dry biomass $\times$ shoot $\mathrm{Mg}^{2+}$ concentration)], and root-to-shoot translocation of $\mathrm{Mg}^{2+}=\left[\left(\right.\right.$ shoot dry biomass $\times$ shoot $\mathrm{Mg}^{2+}$ concentration $) /$ Total $\mathrm{Mg}^{2+}$ content $] \times 100 \%$.

\section{Sequence Blast, Alignment, and Phylogenetic Construction}

To retrieve the protein sequences in angiosperms, lycophytes, mosses, liverworts, algae and fungi, MRS2/MGT proteins in Arabidopsis thaliana were used as queries to blast in Phytozome ${ }^{1}$ and National Center for Biotechnology Information. ${ }^{2}$ The sequences were scored and aligned sequentially using the MUSCLE 3.6 program, ${ }^{3}$ GeneDoc 3.2 (Nicholas, 1997), and CLUSTALX. $^{5}$ The protein matrix was used to plot the MRS2/MGT family tree. The phylogenetic tree was mapped by the MEGA 6.0 program $^{6}$ following the neighbor-joining method, and the bootstrap was analyzed in 1,000 replications. The gene structure was plotted by using GSDS. ${ }^{7}$ Gene accession numbers were listed in Supplementary Table 1.

\footnotetext{
${ }^{1}$ https://phytozome.jgi.doe.gov

${ }^{2}$ https://blast.ncbi.nlm.nih.gov/Blast.cgi

${ }^{3}$ http://www.drive5.com/muscle/

${ }^{4}$ https://www.softpedia.com/get/Science-CAD/GeneDoc.shtml

${ }^{5}$ http://www.clustal.org/clustal2/

${ }^{6}$ https://www.megasoftware.net/history.php

${ }^{7}$ http://gsds.cbi.pku.edu.cn/
} 


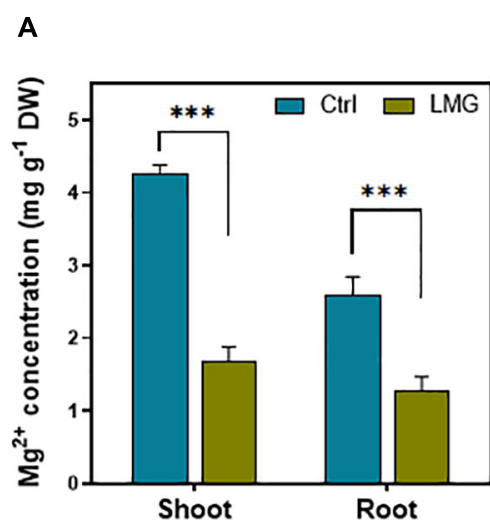

D

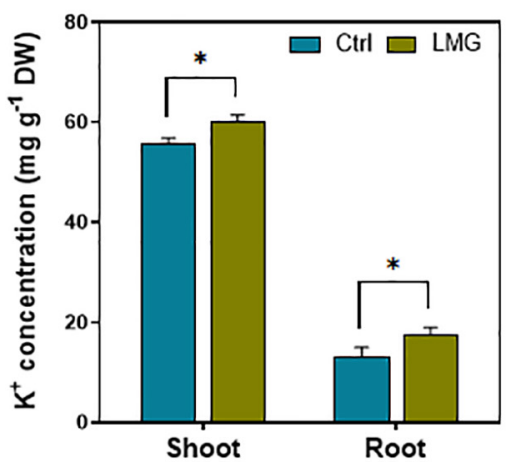

B

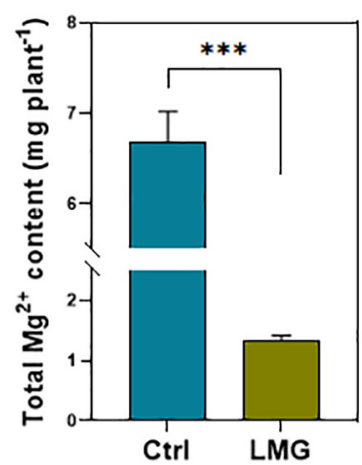

E

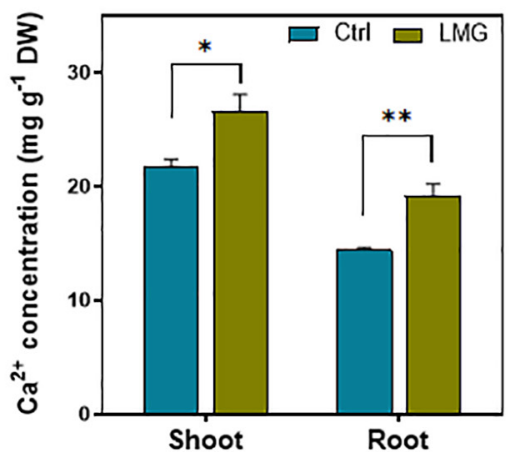

C

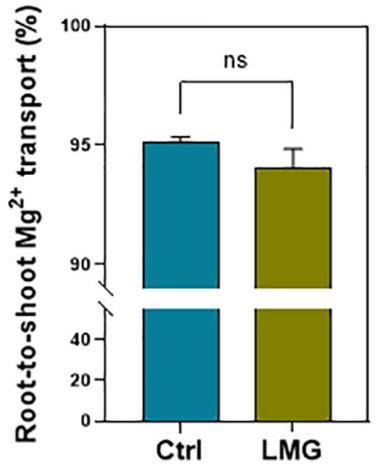

$\mathbf{F}$

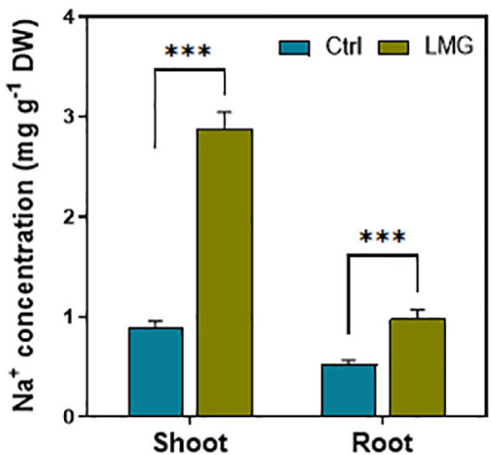

FIGURE 1 | Mg limitation altered $\mathrm{Mg}^{2+}$ uptake and elemental homeostasis in tomato seedlings. (A) $\mathrm{Mg}^{2+}$ concentration in shoot and root (mg $\mathrm{g}^{-1}$ DM), (B) total $\mathrm{Mg}^{2+}$ content (mg pot $\left.{ }^{-1}\right),(\mathbf{C})$ root-to-shoot translocation of $\mathrm{Mg}^{2+}(\%),(\mathbf{D}) \mathrm{K}^{+}$concentration in shoot and root (mg $\mathrm{g}^{-1} \mathrm{DM}^{2}$ ), (E) Ca ${ }^{2+}$ concentration in shoot and root ( $\left.\mathrm{mg} \mathrm{g}^{-1} \mathrm{DM}\right)$, and (F) $\mathrm{Na}^{+}$concentration in shoot and root ( $\left.\mathrm{mg} \mathrm{g}^{-1} \mathrm{DM}\right)$. The bar graph showed the mean value while whiskers represented the maximum/minimum values of six independent biological replicates. Asterisks indicated significant differences at ${ }^{\star} P<0.05$, ${ }^{\star \star} P<0.01$, and ${ }^{\star \star \star} P<0.001$, according to Tukey's HSD test. Where, Ctrl, control; LMG, low Mg; ns, non-significant.

\section{Plant Phenotyping and Root System Analysis}

The root and shoot dry weight was determined after separately drying in the oven at $65^{\circ} \mathrm{C}$ till constant weight. The root-toshoot ratio was calculated on a dry matter basis. Each sample had six independent biological replicates, and each replicate was averaged by two samples harvested from the same pot.

At harvest, the entire root system dissected from the rootshoot junction was rinsed three times by DW and stored at $-4^{\circ} \mathrm{C}$ until scan analysis. Each root was placed on a transparent plastic slide and thoroughly combed apart in DW. The desktop scanner (Epson Perfection V850 Pro) was used to scan the roots at a resolution of $400 \mathrm{dpi}$. The scanned images were analyzed using the WinRHIZO software (version 5.0) (Regent Instruments Inc., Quebec City, QC, Canada) to quantify root indexes as described (Freschet et al., 2020). The relative root growth rate (RRGR) was computed as a given equation (Samal et al., 2010).

$$
R R G R=\left(\frac{\operatorname{In}(T R L 2 / T R L 1)}{t 2-t 1}\right)
$$

Where, $\ln$ is natural $\log , T R L$ is total root length in $\mathrm{cm}$ and $t$ is time of harvest in days; and the subscripts 1 and 2 refer to the 14 and 21 days of harvesting after transfer, respectively.

\section{Extraction and Quantification of Endogenous Hormones}

To analyze dynamic hormonal distribution under Mg limitation, enzyme-linked immunosorbent assay (ELISA) was performed having 96-well microtitration plates filled with extract of plant tissues or hormone standards and corresponding antibodies, according to the standard protocol (EL310, Bio-TEK, Winooski, VT) and the published method (Dai et al., 2009). Briefly, $\sim 0.5 \mathrm{~g}$ frozen plant tissue was fine grounded in a pre-cooled mortar, and homogenized in $10 \mathrm{ml} 80 \%(\mathrm{v} / \mathrm{v})$ methanol extraction medium containing $1 \mathrm{mM}$ butylated hydroxytoluene (BHT) as an antioxidant. Subsequently, the collected extract was incubated at $4^{\circ} \mathrm{C}$ for $4 \mathrm{~h}$, and then centrifuged at $4,000 \mathrm{rpm}$ for $20 \mathrm{~min}$ at $2-4^{\circ} \mathrm{C}$. The supernatant was passed through Chromosep C18 columns (C18 SepPak Cartridges, Waters, Millford, MA), prewashed with absolute methanol. The hormonal fraction was 


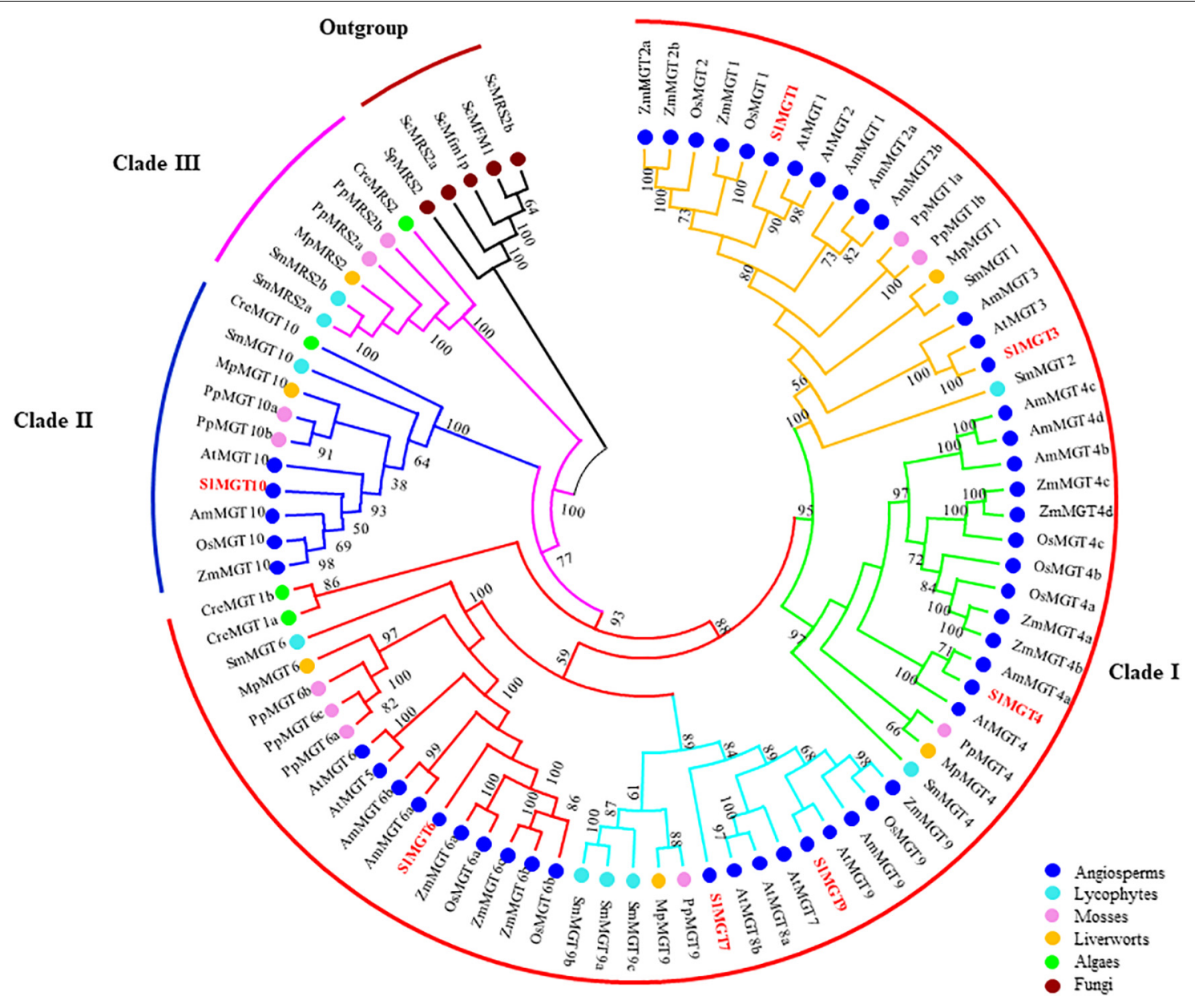

FIGURE 2 | Phylogenetic analysis of the MRS2/MGT gene family in angiosperms, lycophytes, mosses, liverworts, algae and fungi. Three basal clades were indicated by red (Clade 1), blue (Clade II), and purple (Clade III) curves. In Clade 1, MGT1/2/3, MGT4/5, MGT7/8/9, and MGT5/6 branches were in yellow, green, light blue, and red, respectively. Numbers on branches indicated bootstrap values above 50.

eluted with $10 \mathrm{ml}$ of $100 \%(\mathrm{v} / \mathrm{v})$ methanol and then $10 \mathrm{ml}$ ether. The elute was then $\mathrm{N}_{2}$-dried, and dissolved in $2.0 \mathrm{ml}$ phosphate-buffered saline (PBS) containing $0.1 \%(\mathrm{w} / \mathrm{v})$ gelatin and $0.1 \%(\mathrm{v} / \mathrm{v})$ Tween-20 ( $\mathrm{pH} 7.5)$. The concentrations of IAA (indole-3-acetic acid), ABA (abscisic acid), GA3 (gibberellic acid 3 ), and ZR (zeatin riboside) were quantified at an optical density of $A 490$ (Weiler et al., 1981).

\section{RNA Extraction and Quantification by RT-qPCR}

Total RNA was extracted from $\sim 100 \mathrm{mg}$ powdered (in liquid $\mathrm{N}_{2}$ ) tomato samples using the Trizol reagent, following the manufacturer's instructions (Invitrogen). The quality of extracted RNA was checked by a NanoDrop Spectrophotometer. Next, 45 g RNA was digested by DNase 1 (Takara Biomedicals, Kyoto, Japan) to eliminate potential DNA contamination. Reverse transcription of RNA samples into cDNA was carried out using M-MLV reverse transcriptase (Thermo Fisher Scientific, Waltham, MA United States). Quantitative PCR (RT-qPCR) in a Bio-Rad iCycler iQ5 system (Bio-Rad, Hercules, CA, United States) was operated to quantify relative gene expression by using cDNA, SYBR Premix Ex Taq ${ }^{\mathrm{TM}}$ (Takara), and designed primers of genes of interest (Supplementary Table 2). The qPCR was programmed for $10 \mathrm{~min}$ of pre-incubation at $95^{\circ} \mathrm{C}, 40$ cycles of denaturation at $95^{\circ} \mathrm{C}$ for $15 \mathrm{~s}$, annealing at $60^{\circ} \mathrm{C}$ for $30 \mathrm{~s}$, and extension at $72^{\circ} \mathrm{C}$ for $30 \mathrm{~s}$. Four biological and two technical replicates were analyzed for each gene. The housekeeping gene Slubi3 was used as an internal control (Liu S. et al., 2018). The equation $2^{\wedge}$ $(\Delta \Delta \mathrm{Ct})$ was used to determine relative gene expression (Livak and Schmittgen, 2001).

\section{Statistical Analysis}

Data processing with simple calculations (e.g., mean, standard deviation [SD], maximum and minimum) was performed by Microsoft Excel-2019. One-way analysis of variance (ANOVA) along with the Tukey honest significant difference (HSD) test was performed by Statistix 8.1 (Analytical Software, Tallahassee, FL, United States) to analyze the statistical difference 


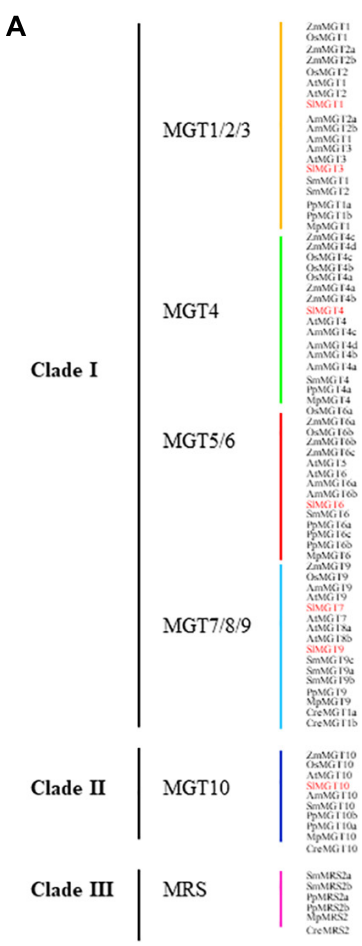

B

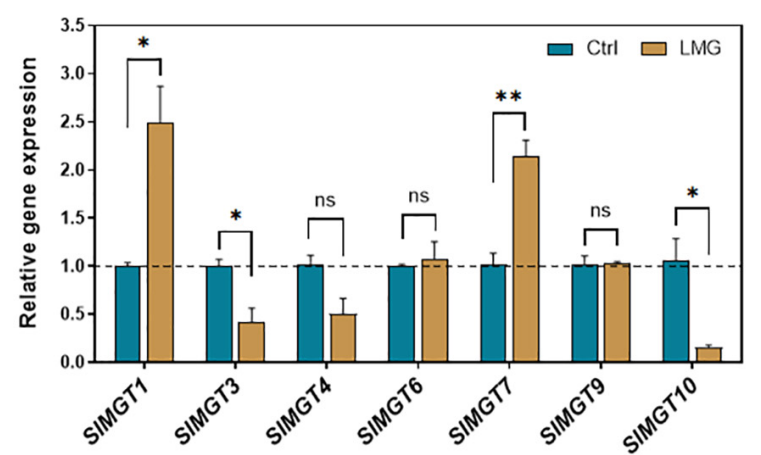

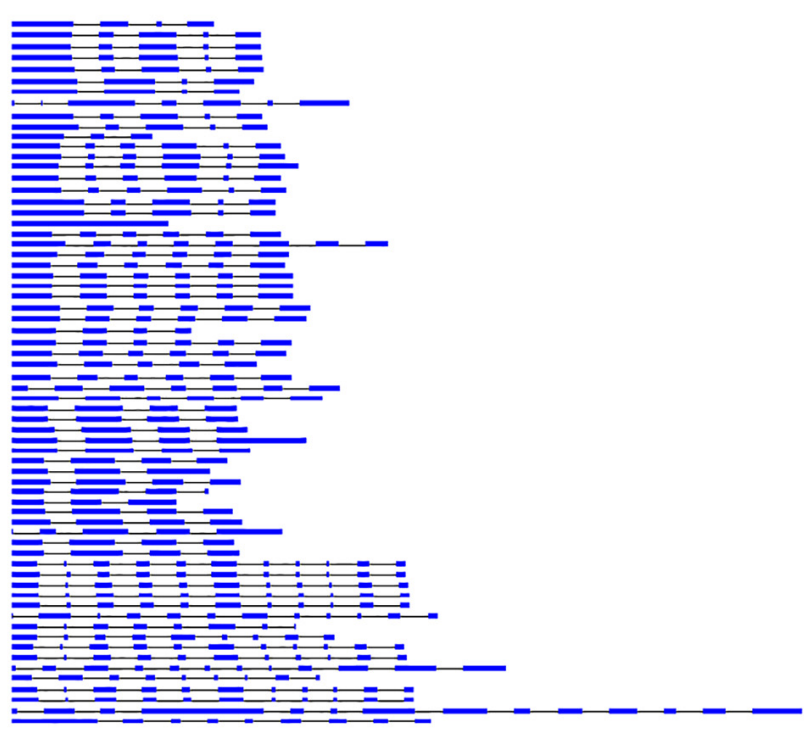
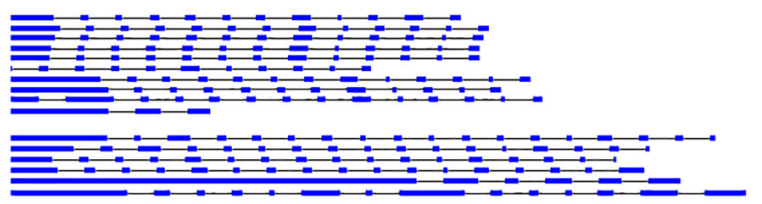

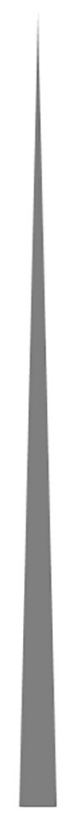

C

Fold change in root

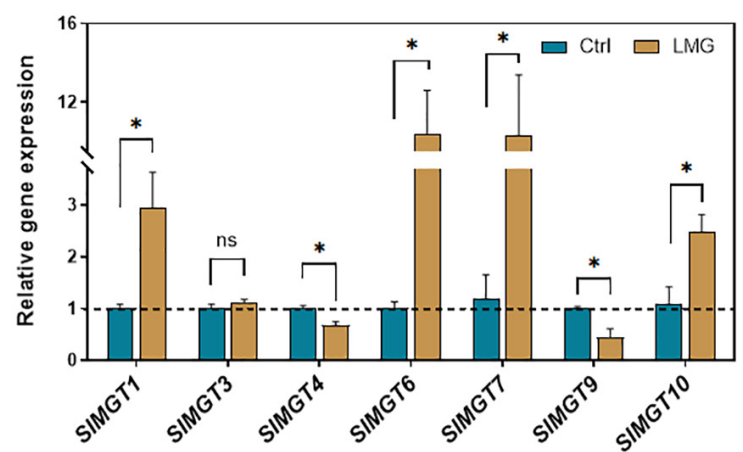

FIGURE 3 | The gene structure of MGTs, and transcription patterns of MGTs in LMG seedlings. (A) Gene structure of MRS2/MGT-type Mg transporters, (B) relative gene expression of MGTs in the shoot, and (C) relative gene expression of MGTs in the root. The values of MGTS were reported as relative fold change from control, which was normalized to 1 as shown by dashed horizontal lines. The bar graph showed the mean value while whiskers represented the maximum/minimum values of four independent biological replicates. Asterisks indicated significant differences at ${ }^{*} P<0.05$ and ${ }^{* *} P<0.01$, according to Tukey's HSD test. Where, Ctrl, control; LMG, low Mg; MGT, Mg transporter; ns, non-significant.

$\left({ }^{*} P<0.05,{ }^{* *} P<0.01,{ }^{* * *} P<0.001\right)$ across treatments, as specified in figure legends. Bar graphs were plotted by GraphPad Prism 9.

\section{RESULTS}

\section{Elemental Homeostasis Under Magnesium Limitation}

The data of elemental homeostasis showed an obvious variation among treatments. The $\mathrm{Mg}^{2+}$ concentration significantly reduced from 2.6 to $1.29 \mathrm{mg} \mathrm{g}^{-1}(\sim 50 \%)$ in the tomato root, and $4.27-\mathrm{mg} \mathrm{g}^{-1}(\sim 61 \%)$ in the shoot under $\mathrm{Mg}$ limitation, compared to control (Figure 1A). The total $\mathrm{Mg}^{2+}$ content in the Mg-sufficient seedling was significantly higher by $\sim 80 \%$, compared to LMG plants (Figure 1B). Out of whole plant $\mathrm{Mg}^{2+}$ uptake, we did not find significant variations in percent rootto-shoot translocation of $\mathrm{Mg}^{2+}$ among treatments (Figure 1C). Importantly, during $\mathrm{Mg}$ limitation, the concentration of other competing cations such as $\mathrm{K}^{+}, \mathrm{Ca}^{2+}$, and $\mathrm{Na}^{+}$significantly increased by 34,33 , and $85 \%$ in the root, respectively. In the shoot, $\mathrm{K}^{+}, \mathrm{Ca}^{2+}$, and $\mathrm{Na}^{+}$concentrations significantly 


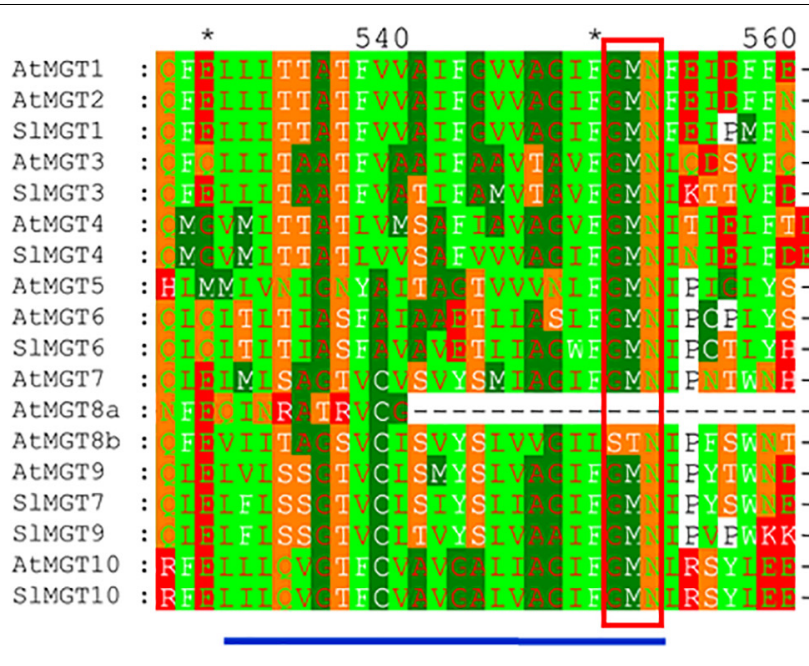

TM1
TM2

FIGURE 4 | The alignment of SIMGT and ATMGT proteins. Conserved residues of each group of MRS2/MGTs were shaded in different colors. GMN (Gly-Met-Asn) tripeptide motif was indicated by red bar. Dashes represented gaps in the sequence and conserved residues that constituted the active sites were marked by asterisk. Numbers above the alignment gave the position of an amino acid within the alignment. Where, TM, transmembrane localization.

increased by $9,22 \%$, and $\sim 2$-fold, respectively, compared to control (Figures 1D-F).

\section{Evolutionary Analysis of the MRS2/MGT-Type Magnesium Transporter Family and MGTs Expression in Response to Magnesium Limitation}

To better select and analyze expression levels of representative $\mathrm{Mg}$ transporters, we constructed the phylogenetic tree of the MRS2/MGT-type Mg transporter family by retrieving corresponding protein sequences of Solanum lycopersicum, Arabidopsis thaliana, Oryza sativa, Zea mays, Amborella trichopoda, Selaginella moellendorffi, Physcomitrella patens, Marchantia polymorpha, and Chlamydomonas reinhardtii, with fungal MRSs as an out-group. Phylogenetic analysis showed that MRS2/MGT constitutes a previously uncharacterized 3-basal clade in planta with two rounds of asymmetric duplications. Briefly, Clade I split into four subclades (MGT1/2/3, MGT4, MGT5/6, MGT7/8/9), and Clade II(MGT1/2/3, MGT4the MGT10 subfamily. Clade I and Clade II contained members across angiosperms, lycophytes, mosses, liverworts, and algae, while Clade III had no members from angiosperms (Figure 2). The gene structure of the MRS2/MGT family also supported such a three-clade pattern, as shown in Figure 3A. The average exon number showed obvious changes across clades I, II, and III and average exon 1-12, 11-14, 6-18 exons, respectively. Less exons of MGT1/2/3, MGT4, and MGT5/6 are probably due to intron losses in these subfamilies during evolution.

We suspected that reduced $\mathrm{Mg}$ accumulation in LMG seedlings was primarily attributed to differential expression (and further functioning) of Mg transporters. RT-qPCR results showed that $\mathrm{Mg}$ limitation stimulated expression MGT1 and MGT7 by 2.5 - and 2.1 -fold, respectively, in the shoot. Meanwhile, MGT3 and MGT10 expression was significantly down-regulated to 0.42 - and 0.16 -fold, respectively, in the shoot of LMG seedlings (Figure 3B). In the root, MGT1, MGT6, MGT7, and MGT10 had 2. 9-, 10. 4-, 10. 3-, and 2.5-fold higher levels of transcription under $\mathrm{Mg}$ limitation, respectively. Meanwhile, the expression of MGT4 and MGT9 was down-regulated to $0.68-$ and 0.44 -fold, respectively, in the LMG root, as shown in Figure 3C. Further, the alignment of SIMGT and ATMGT proteins showed that all differentially expressed MRS2/MGTs in tomato had two typical transmembrane domains and a GMN (Gly-Met-Asn) tripeptide motif (Figure 4).

\section{Plant Biomass and Root Architectural Indexes of Low Magnesium Seedlings}

$\mathrm{Mg}$ limitation significantly reduced root and shoot dry biomass compared to control, with $\sim 50$ and 36\% decreases, respectively (Figures $\mathbf{5 A - C}$ ). Interestingly, the percentage reduction in root biomass was higher compared to that in shoot biomass, which contributed to a $\sim 47 \%$ decrease of the root/shoot ratio of $\mathrm{Mg}$-depleted plants, compared to control plants (Figure 5D).

Entire roots were scanned to examine treatment effects on root system architecture (Figure 5E). Root morphological indexes revealed a significant $(P<0.01)$ reduction in total root length $(\sim 49 \%)$, root surface area $(\sim 50 \%)$, and length per volume $(\sim 49 \%)$ in Mg-depleted plants, compared to control (Figures 5F-H). Whereas, average root diameter $(\mathrm{mm})$ did not show significant differences as shown in Figure 5I. We also observed a sharp decline in the overall root system after the 14-day treatment (Supplementary Figure 1). To 
A

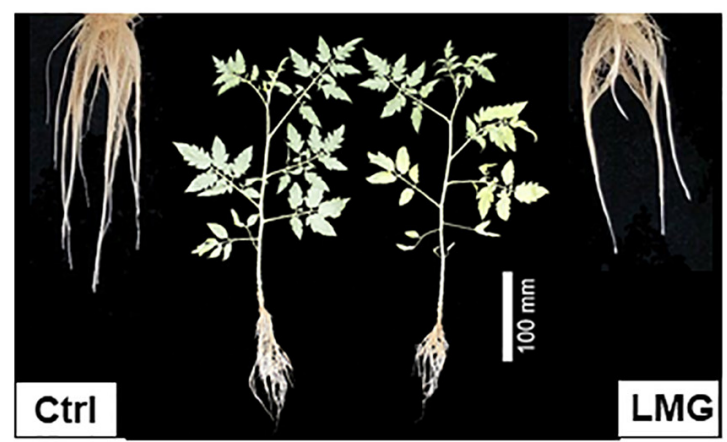

B

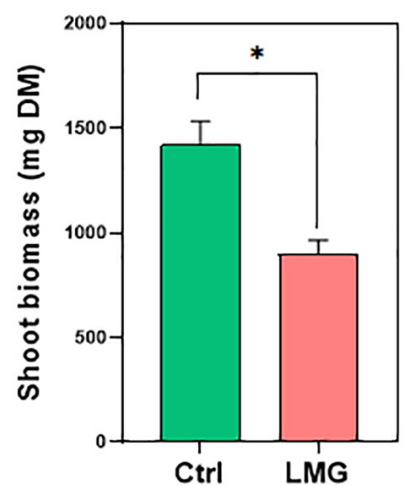

D

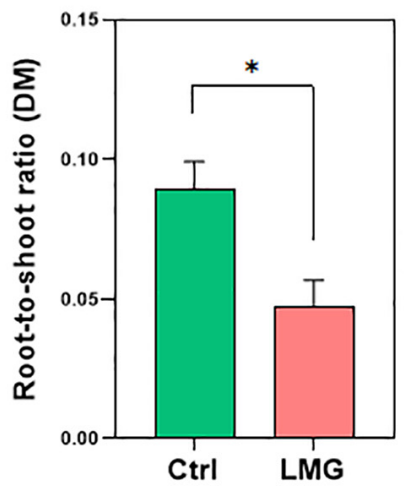

G

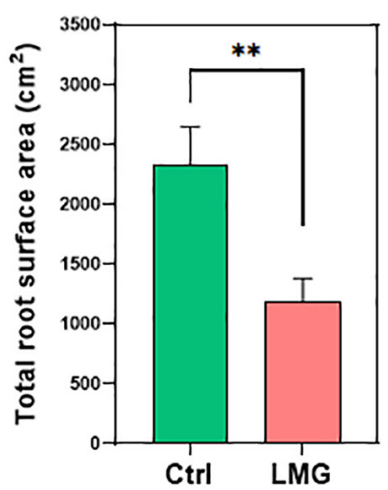

E

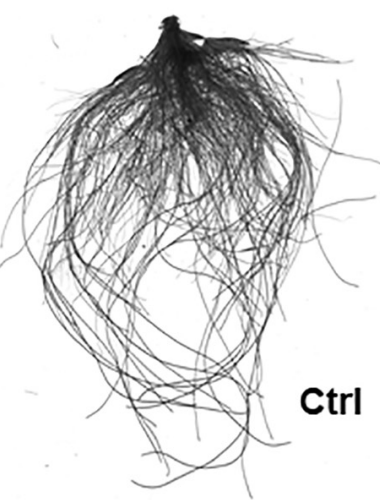

H

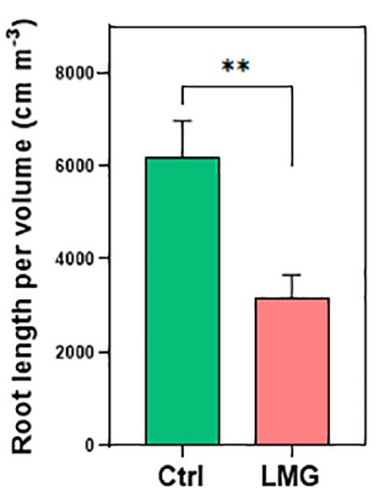

C

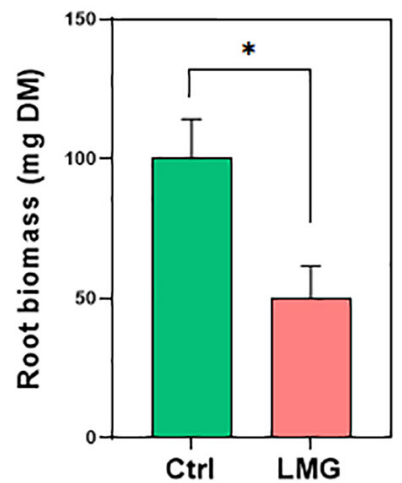

F
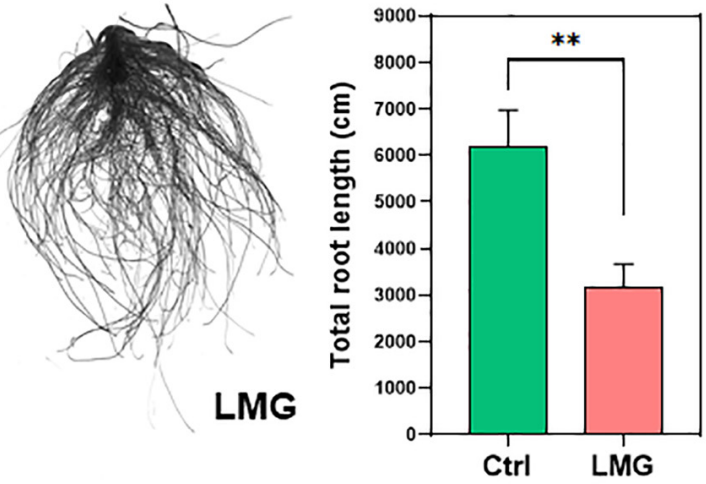

J
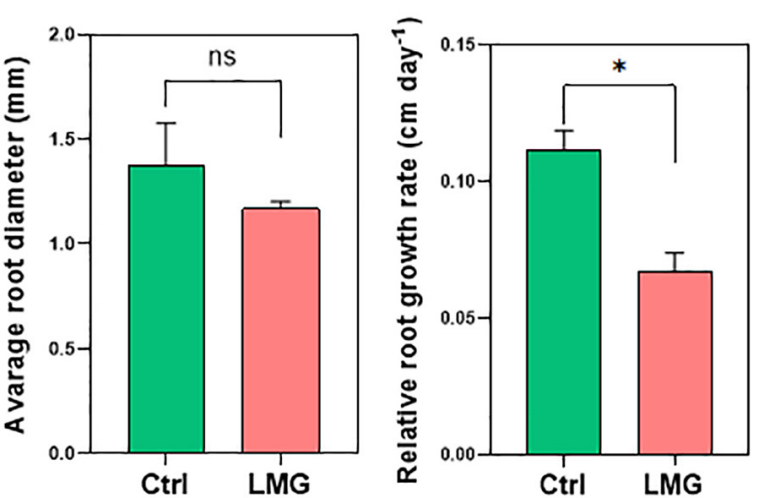

FIGURE 5 | Mg limitation inhibited tomato growth and root architectural indexes. (A) Plant phenotypic responses after 3 weeks of treatments, (B) Root biomass (mg plant $^{-1} \mathrm{DM}$ ), (C) Shoot biomass (mg plant $\left.{ }^{-1} \mathrm{DM}\right)$, (D) Root-to-shoot ratio (DM), (E) Scanned image of control and LMG treated roots (F) Total root length (cm), (G) Total root surface area $\left(\mathrm{cm}^{2}\right)$, (H) Root length per volume $\left(\mathrm{cm} \mathrm{m}^{-3}\right)$, (I) Average root diameter $(\mathrm{mm})$, and $(\mathbf{J})$ Relative root growth rate $\left(\mathrm{cm}\right.$ day $\left.{ }^{-1}\right)$. The bar graph showed the mean value while whiskers represented the maximum/minimum values of six independent biological replicates. Asterisks indicated a significant difference at ${ }^{\star} P<0.05$ and ${ }^{\star \star} P<0.01$, according to Tukey's HSD test. Where, Ctrl, control; LMG, low Mg; ns, non-significant.

better understand the dynamic change of root growth, we computed relative root growth rate (RRGR) by harvesting tomato seedlings on day 14 and 21 after treatments. Results showed $0.07 \mathrm{~cm} \mathrm{day}^{-1}$ root growth under $\mathrm{Mg}$ limitation in contrast to $0.11 \mathrm{~cm} \mathrm{day}{ }^{-1}$ growth of control roots (Figure 5J).

\section{Magnesium Deficiency-Induced} Hormonal Distribution and Expression Patterns of Auxin Biosynthesis

Below- and above-ground hormonal accumulation differed apparently under LMG, as shown in Figures 6A-D. The 
A

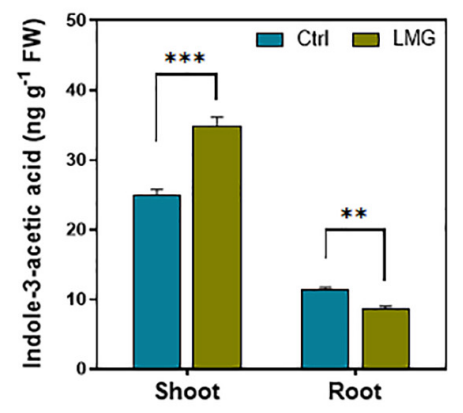

C

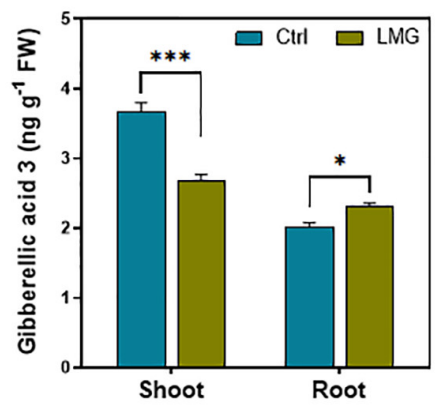

E Fold change in shoot

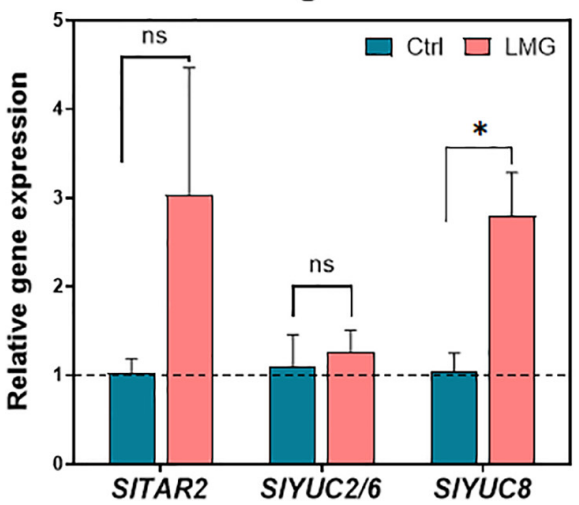

B

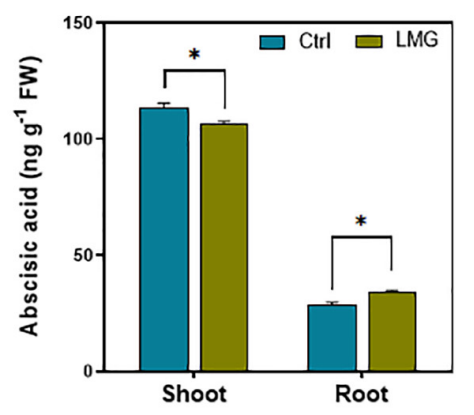

D

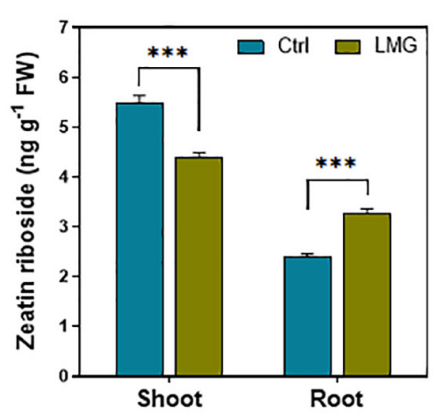

Fold change in root

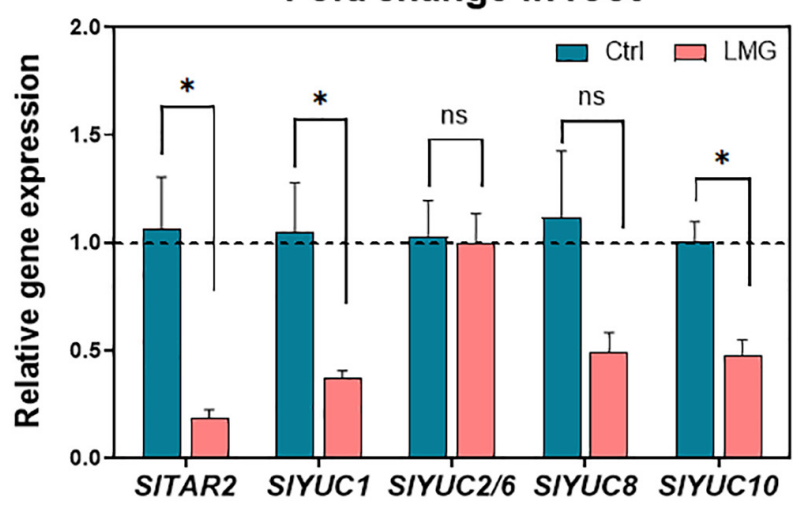

FIGURE 6 | LMG disturbed the hormonal distribution and expression patterns of auxin biosynthesis in the root. (A) Indole-3-acetic acid concentration in shoot and root ( $\mathrm{ng} \mathrm{g} \mathrm{g}^{-1} \mathrm{FW}$ ), (B) Abscisic acid concentration in shoot and root (ng g $\mathrm{g}^{-1} \mathrm{FW}$ ), (C) Gibberellic acid 3 concentration in shoot and root (ng g ${ }^{-1} \mathrm{FW}$ ), (D) Zeatin riboside concentration in shoot and root (ng g ${ }^{-1} \mathrm{FW}$ ), (E) Relative gene expression of TAR/YUCs in the shoot, (F) Relative gene expression of TAR/YUCs in the root. The bar graph showed the mean value while whiskers represented the maximum/minimum values of four independent biological replicates. Asterisks indicated significant differences at ${ }^{\star} P<0.05,{ }^{\star \star} P<0.01$, and ${ }^{\star \star \star} P<0.001$, according to Tukey's HSD test. Where, Ctrl, control; LMG, low Mg; ns, non-significant; YUC, YUCCA.

concentration of endogenous indole-3-acetic acid (IAA) was $40 \%$ higher (increased from 25 to $35 \mathrm{ng} \mathrm{g}^{-1}$ ) in the shoot of $\mathrm{Mg}$ deficient plants. However, the IAA concentration surprisingly decreased by $23 \%$ (to $8.69 \mathrm{ng} \mathrm{g}^{-1}$ ) in the root of $\mathrm{Mg}$ deficient plants, compared to control plants (Figure 6A), possibly due to diminished shoot-to-root IAA translocation under $\mathrm{Mg}$ limitation. Contradictory to the IAA accumulation pattern, other hormones displayed significantly higher accumulation in the root as compared to that in the shoot under $\mathrm{Mg}$ limitation: concentrations of $\mathrm{ABA}, \mathrm{GA} 3$ and $\mathrm{ZR}$ reduced by 18,27 , and 20\%, respectively, in LMG shoot. Meanwhile, approximately 6, 14, and 36\% more ABA, GA3, and ZR, respectively, were detected in the $\mathrm{LMG}$ root, compared to control (Figures 6B-D).

In LMG shoot, the YUC8 was upregulated by 2.8 -fold and the expression of other auxin synthesis related genes, i.e., TAR2, YUC2/6, and YUC8 remained unchanged (Figure 6E). Consistent with lower IAA concentrations in LMG roots, TAR2, YUC1, YUC8, and YUC10 showed 0. 18-, 0. 37-, 0. 49-, and 0.48 -fold down-regulation in the root under $\mathrm{Mg}$ limitation. However, YUC2/6 and YUC8 showed no significant change in expression (Figure 6F). 
A

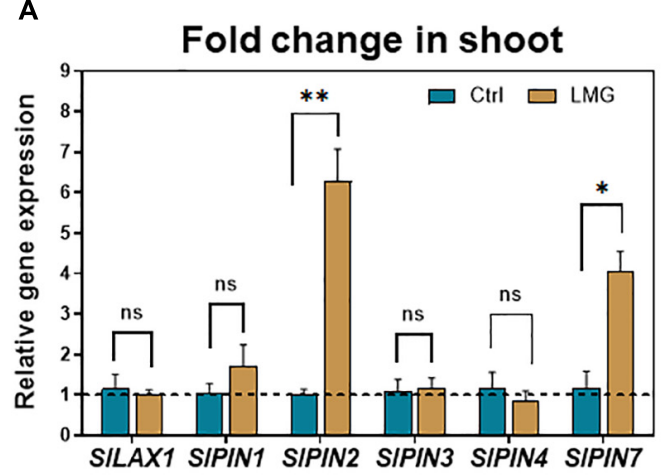

C

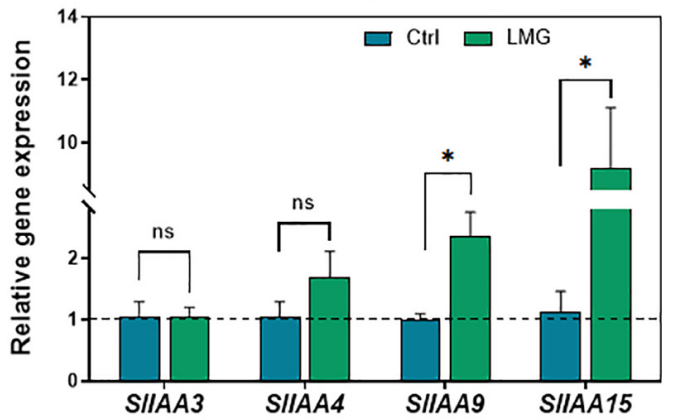

E

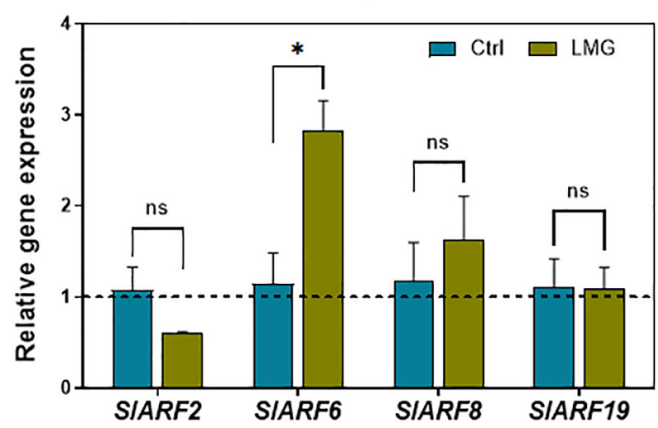

B

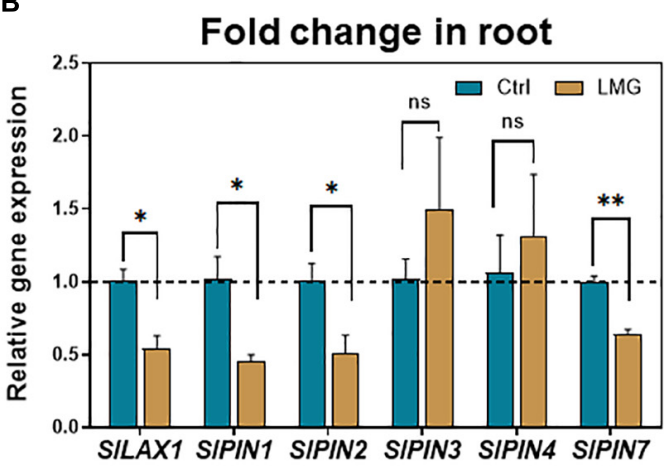

D

Fold change in root

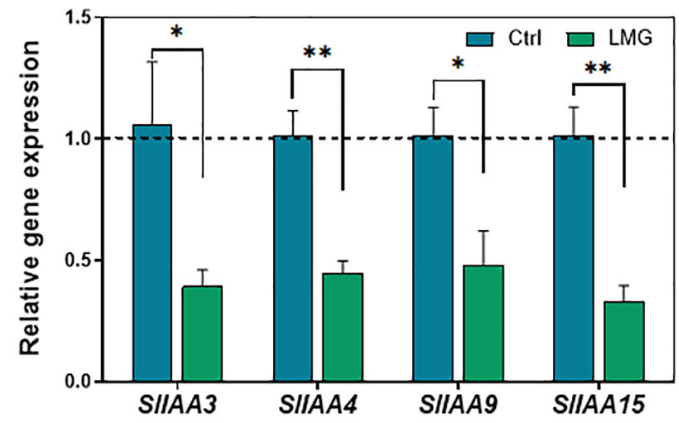

$\mathbf{F}$

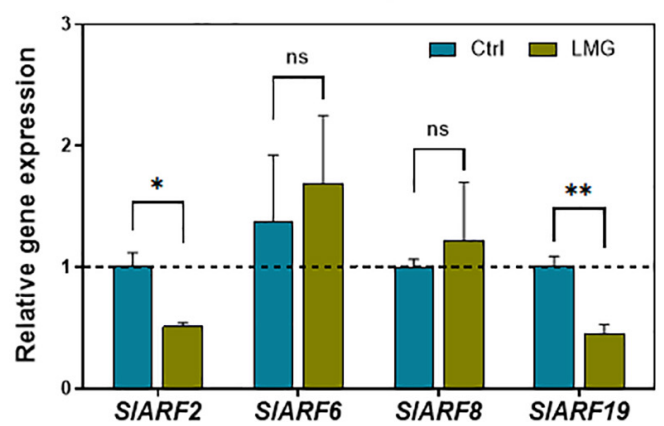

FIGURE 7 | Transcriptional alterations of auxin transport and signaling genes under Mg limitation. (A) Relative gene expression of LAX/PINs in the shoot, (B) Relative gene expression of LAXIPINs in the root, (C) Relative gene expression of IAAs in the shoot, (D) Relative gene expression of IAAs in the root, (E) Relative gene expression of ARFs in the shoot, (F) Relative gene expression of ARFs in the root. The values were reported as relative fold change from control, which was normalized to 1 as shown by dashed horizontal lines. The bar graph showed the mean value while whiskers represented the maximum/minimum values of four independent biological replicates. Asterisks indicated a significant difference at ${ }^{*} P<0.05,{ }^{\star \star} P<0.01$, according to Tukey's HSD test. Where, Ctrl, control; LMG, low Mg; ns, non-significant; LAX, LIKE-AUX1; PIN, PIN-FORMED; AuX/IAA, AUXIN/INDOLE ACETIC ACID; ARFs, AUXIN RESPONSE FACTORS.

\section{Transcriptional Alterations of Auxin Transport and Signaling Genes Under Magnesium Limitation}

To further investigate the potential implications of auxin signaling in modulating root growth under $\mathrm{Mg}$ limitation, we quantified the expression of genes regulating auxin transport and signaling by RT-qPCR. With regard to auxin transport, PIN2 and PIN7 showed higher expression levels in the LMG shoot compared with control. No significant variation in expression of LAX1, PIN1, PIN3, and PIN4 was observed in the Mgdepleted shoot (Figure 7A). In the LMG root, transcription of 


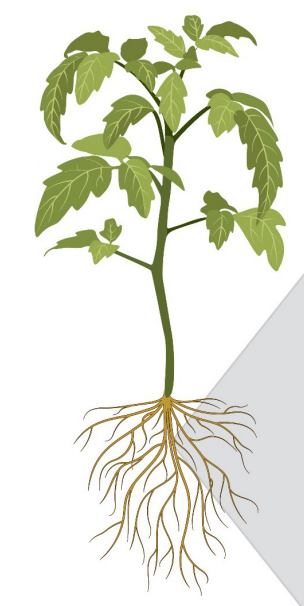

LMG supply

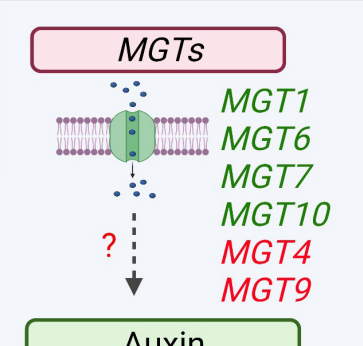

Auxin

biosynthesis
Up-regulated

Impaired accumulation/down-regulated

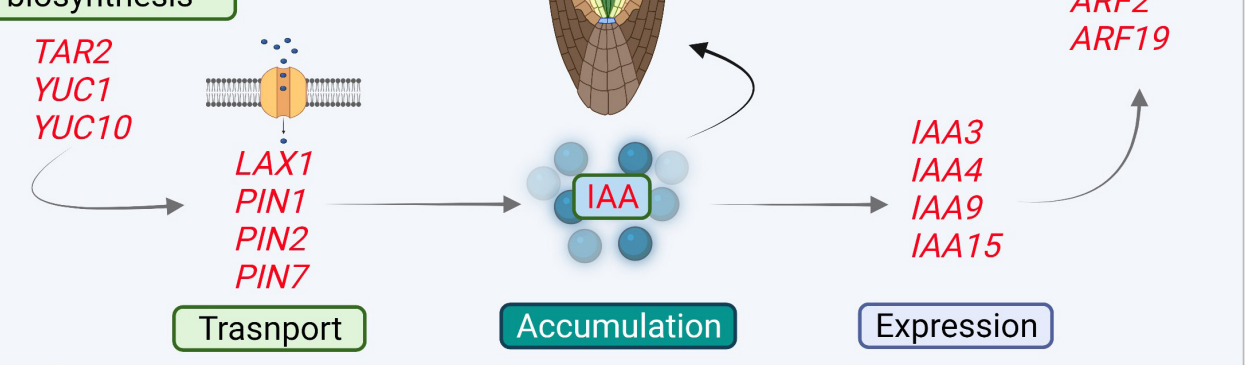

FIGURE 8 | Scheme depicting the impaired auxin accumulation and signaling in Mg-deficient root. Differential expression of MGTs in the root favors Mg uptake and translocation under $\mathrm{Mg}$ limitation. Low Mg leads to smaller root related indexes. In the root, Mg limitation down-regulates gene expression along auxin synthesis, transport, and signal transduction. Where, MGTS, Mg transporters; YUC, YUCCA; LAX, LIKE-AUX1; PIN, PIN-FORMED; AuX/IAA, AUXIN/INDOLE ACETIC ACID; ARFS, AUXIN RESPONSE FACTORS.

LAX1, PIN1, PIN2, and PIN7 was significantly repressed to 0 . 54-, 0. 45-, 0. 51-, and 0.64-fold, respectively, compared with control. However, PIN3 and PIN4 showed no significant change in expression (Figure 7B).

Beyond auxin transport is its signaling that orchestrates complicated physiological outcomes (Lv et al., 2020; Meier et al., 2020; Hu et al., 2021), therefore we analyzed expression of related $I A A$ and $A R F$ genes. Mg limitation led to significant upregulation of IAA9 and IAA 15 by 2.35- and 9.2-fold, respectively, in the LMG shoot (Figure 7C) in contrast to down-regulation of IAA3, IAA4, IAA9, and IAA15 by 0. 39-, 0. 45-, 0. 48-, and 0.33 -fold, respectively, in the LMG root (Figure 7D). Lastly, ARF genes had differential expression in the shoot and root under $\mathrm{Mg}$ limitation, too. ARF6 had 2.8-fold higher expression in the LMG shoot, with no change in expression of ARF2, ARF8, and ARF19, compared with control (Figure 7E). Different from expression patterns in the shoot, no ARF expression was stimulated by $\mathrm{Mg}$ limitation in the root, while ARF2 and ARF19 expression was down-regulated by 0.51 - and 0.45 -fold, respectively, compared to control (Figure 7F).

\section{DISCUSSION}

$\mathrm{Mg}$ plays fundamental roles in regulating crop production and produce quality, and $\mathrm{Mg}$ deficiency is emerging as an increasing agricultural and nutritional issue required to be tackled worldwide (Hauer-Jákli and Tränkner, 2019; Wang et al., 2020;
Fiorentini et al., 2021). However, how plants adapt to $\mathrm{Mg}$ deficiency stress remains largely unclear or inconsistent. Here, we presented a previously uncharacterized 3-clade tree for $\mathrm{Mg}$ transporters in planta, revealed up-regulation of six representative MGTs in $\mathrm{Mg}$-deficient tomato seedlings, and characterized a smaller root system harboring coherent downregulation of auxin accumulation and expression of related genes in auxin signaling in an important horticultural model crop, providing new valuable insights for future studies.

\section{Differential Expression of MGTs in Tomato Seedlings Favors $\mathbf{M g}^{2+}$ Uptake and Translocation in Response to Low Magnesium}

In our study, tomato seedlings suffered from $\mathrm{Mg}$ deficiency from the first day of transplanting into the nutrient solution which may avoid $\mathrm{Mg}^{2+}$ accumulation in the vacuole during initial growth stages (Hauer-Jákli and Tränkner, 2019). Mg limitation reduced $\mathrm{Mg}^{2+}$ uptake by tomato roots (Figures 1A,B). Low eternal $\mathrm{Mg}$ conditions also disturbed elemental homeostasis by increasing uptake of other competing cations, i.e., $\mathrm{K}^{+}, \mathrm{Ca}^{2+}$, and $\mathrm{Na}^{+}$. To analyze expression of representative $M G T s$, we generated a unified three-clade phylogenetic tree of the MRS2/MGT gene family (Figure 2), which provided the evolutionary foundation for future functional characterization of MGTs. In Arabidopsis, MGT6 regulates cellular homeostasis of $\mathrm{Mg}^{2+}$ under $\mathrm{Mg}$ limitation (Mao et al., 2014; Oda et al., 2016; Yan et al., 2018). 
Mg limitation results in higher MGT1 expression in Arabidopsis (Lenz et al., 2013) and rice (Zhang et al., 2019b). In tomato, all differentially expressed MGTs fell into clade I except MGT10 in clade II (Figures 2, 3A). In total, six MGTs showed differential expression between control and LMG seedlings, and four upregulated (MGT1, MGT6, MGT7, and MGT10) transporters in root probably favored $\mathrm{Mg}^{2+}$ uptake and translocation (Figure 3C). Differential expression of MGT1, MGT3, MGT7, and MGT10 in the shoot possibly manipulate $\mathrm{Mg}^{2+}$ translocation within plant tissues under $\mathrm{Mg}$ limitation (Figure 3B). The relative functional importance of these MGTs in tomato adaptation to $\mathrm{Mg}$ limitation calls for further studies to unravel underlying molecular mechanisms.

\section{Transcriptional Down-Tuning of Genes Regulating Auxin Biosynthesis, Transport, and Signaling Conditioned a Smaller Seedling Root Under Magnesium Limitation}

Root growth is largely programmed by internal genetic, developmental cues and various environmental stimuli primarily via hierarchical hormone signaling cascades (Lakehal and Bellini, 2019; Alaguero-Cordovilla et al., 2021; Hu et al., 2021). Auxin plays a central role in root initiation, elongation, and architectural configuration (Olatunji et al., 2017; Meier et al., 2020; Sun et al., 2020). YUCs overexpression promotes IAA production in Arabidopsis (Mashiguchi et al., 2011; Novak et al., 2012). Here, TAR2, YUC1, YUC8, and YUC10 downregulated by 0. 18-, 0. 37-, 0. 49-, and 0.48-fold in Mg-depleted roots (Figure 6F), suggesting that $\mathrm{Mg}$ limitation impairs IAA synthesis. Consistently, IAA accumulation decreased by $\sim 23 \%$ in the root in contrast to the $\sim 40 \%$ increase in the shoot under $\mathrm{Mg}$ limitation (Figure 6A), clearly suggesting that $\mathrm{Mg}$ limitation reshaped auxin synthesis and distribution pattern between above- and below-ground. Such significant lower levels of auxin ultimately converted into developmental cues to slow down root growth.

Auxin transport and signaling components play essential roles in root system development (Porco et al., 2016; Du and Scheres, 2018; Hu et al., 2021). AUX/LAX, PIN2, PIN3, and PIN7 all participate in root development (Paponov et al., 2005; Marhavy et al., 2013). Our results showed significant transcriptional repression of LAX1, PIN1, PIN2, and PIN7 in the LMG root (Figure 7A), in agreement with lower levels of auxin. Aux/IAA is a key regulator of auxin-modulated signal transduction (Chandler, 2016; Israeli et al., 2020; Lv et al., 2020). In our study, expression of IAA3, IAA4, IAA9, and IAA15 was depressed in the LMG root (Figure 7D). Further, ARF2 and $A R F 19$ expression was highly down-regulated in the root under Mg limitation (Figure 7F). The transcriptional activators ARF7 and ARF19 play an important role in root branching (Lee et al., 2019). Based on the actual expression levels, it is speculated that the relative strong expressed genes such as MGT7, TAR2, YUC1, PIN1, PIN2, PIN7, IAA4, IAA15, and ARF2 may altered the auxin-related process in Mg-deficient roots. Hence, on the basis of consistent decreases in auxin accumulation and attenuation of related gene expression along auxin signaling in the LMG root
(Figures 6, 7), we propose that LMG led to weakened auxin functioning, i.e., synthesis, transport, accumulation, and signal transduction in the root system (Figure 8).

The work presented in this study provides a new valuable insight that LMG supply disturbs transcription of auxin signaling genes, which well fit in the phenotype of smaller roots. However, in future detailed molecular investigation with mutant lines and protein functions is required to directly link such phenotypes to auxin signaling. In summary, given the crucial roles of auxin in modulating root growth, it is speculated that down-tuning of auxin accumulation and signaling in the root preconditions smaller root related indexes, while expression of MGTs are mostly up-regulated for $\mathrm{Mg}$ uptake and translocation.

\section{CONCLUSION}

Phylogenetic analysis suggested that $\mathrm{Mg}$ transporters (MRS2/MGTs) constitute a previously uncharacterized 3clade tree in planta. In adaptation to internal $\mathrm{Mg}$ deficiency, tomato seedlings altered MGTs expression under Mg limitation. Notably, lower auxin (IAA) accumulation in Mg-deficient roots was consistent with systemic down-tuning of gene expression in auxin synthesis (TAR/YUCs), transport (LAXs, PINs), and signaling (IAAs, ARFs). Given the crucial roles of auxin in modulating root growth, it is speculated that weakened auxin functioning under $\mathrm{Mg}$ limitation may precondition a smaller root system. Further efforts are required to better understand the molecular functioning of MRS2/MGTs, auxin signaling and its involvement in modulating root growth under $\mathrm{Mg}$ limitation.

\section{DATA AVAILABILITY STATEMENT}

The datasets presented in this study can be found in online repositories. The names of the repository/repositories and accession number(s) can be found in the article/Supplementary Material.

\section{AUTHOR CONTRIBUTIONS}

MI and XL conceived, designed the study, wrote, and revised the manuscript. MI and YW performed the experiments. MI and YZ analyzed the data. All authors have reviewed and approved the submitted version.

\section{FUNDING}

This work was supported by the National Natural Science Foundation of China (32172663).

\section{SUPPLEMENTARY MATERIAL}

The Supplementary Material for this article can be found online at: https://www.frontiersin.org/articles/10.3389/fpls.2021. 802399/full\#supplementary-material 


\section{REFERENCES}

Ahmad, Z., Nadeem, F., Wang, R., Diao, X., Han, Y., Wang, X., et al. (2018). A larger root system is coupled with contrasting expression patterns of phosphate and nitrate transporters in foxtail millet [Setaria italica (L.) Beauv.] under phosphate limitation. Front. Plant Sci. 9:1367. doi: 10.3389/fpls.2018. 01367

Alaguero-Cordovilla, A., Belen Sanchez-Garcia, A., Ibanez, S., Albacete, A., Cano, A., Acosta, M., et al. (2021). An auxin-mediated regulatory framework for wound-induced adventitious root formation in tomato shoot explants. Plant Cell Environ. 44, 1642-1662. doi: 10.1111/pce.14001

Bhosale, R., Giri, J., Pandey, B. K., Giehl, R. F. H., Hartmann, A., Traini, R., et al. (2018). A mechanistic framework for auxin dependent Arabidopsis root hair elongation to low external phosphate. Nat. Commun. 9:1818. doi: 10.1038/ s41467-018-04281-x

Broadley, M. R., and White, P. J. (2010). Eats roots and leaves. Can edible horticultural crops address dietary calcium, magnesium and potassium deficiencies? Proc. Nutr. Soc. 69, 601-612. doi: 10.1017/S00296651100 01588

Cámara-Zapata, J. M., Brotons-Martínez, J. M., Simón-Grao, S., Martinez-Nicolás, J. J., and García-Sánchez, F. (2019). Cost-benefit analysis of tomato in soilless culture systems with saline water under greenhouse conditions. J. Sci. Food Agric. 99, 5842-5851. doi: 10.1002/jsfa.9857

Chandler, J. W. (2016). Auxin response factors. Plant Cell Environ. 39, 1014-1028. doi: $10.1111 /$ pce. 12662

Chen, Z. C., Peng, W. T., Li, J., and Liao, H. (2018). Functional dissection and transport mechanism of magnesium in plants. Semin. Cell Dev. Biol. 74, 142-152. doi: 10.1016/j.semcdb.2017.08.005

Chen, Z. C., Yamaji, N., Horie, T., Che, J., Li, J., An, G., et al. (2017). A magnesium transporter OsMGT1 plays a critical role in salt tolerance in rice. Plant Physiol. 174, 1837-1849. doi: 10.1104/pp.17.00532

Cui, Y., Zhao, S., Wang, X., and Zhou, B. (2016). A novel Drosophila mitochondrial carrier protein acts as a $\mathrm{Mg}^{2+}$ exporter in fine-tuning mitochondrial $\mathrm{Mg}^{2+}$ homeostasis. Biochim. Biophys. Acta 1863, 30-39. doi: 10.1016/j.bbamcr.2015. 10.004

Dai, X. Y., Su, Y. R., Wei, W. X., Wu, J. S., and Fan, Y. K. (2009). Effects of top excision on the potassium accumulation and expression of potassium channel genes in tobacco. J. Exp. Bot. 60, 279-289. doi: 10.1093/jxb/ern285

Du, Y., and Scheres, B. (2018). Lateral root formation and the multiple roles of auxin. J. Exp. Bot. 69, 155-167. doi: 10.1093/jxb/erx223

Farhat, N., Elkhouni, A., Zorrig, W., Smaoui, A., Abdelly, C., and Rabhi, M. (2016). Effects of magnesium deficiency on photosynthesis and carbohydrate partitioning. Acta Physiol. Plant. 38:145. doi: 10.1007/s11738-0162165-Z

Fiorentini, D., Cappadone, C., Farruggia, G., and Prata, C. (2021). Magnesium: biochemistry, nutrition, detection, and social impact of diseases linked to its deficiency. Nutrients 13:1136. doi: 10.3390/nu13041136

Freschet, G., Pagès, L., Iversen, C., Comas, L., Rewald, B., Roumet, C., et al. (2020). A starting guide to root ecology: strengthening ecological concepts and standardizing root classification, sampling, processing and trait measurements. New Phytol. 232, 973-1122. doi: 10.1111/nph. 17572

Gerendás, J., and Führs, H. (2013). The significance of magnesium for crop quality. Plant Soil 368, 101-128. doi: 10.1007/s11104-012-1555-2

Gruber, B. D., Giehl, R. F. H., Friedel, S., and von Wirén, N. (2013). Plasticity of the Arabidopsis root system under nutrient deficiencies. Plant Physiol. 163, 161-179. doi: 10.1104/pp.113.218453

Guseman, J. M., Hellmuth, A., Lanctot, A., Feldman, T. P., Moss, B. L., Klavins, E., et al. (2015). Auxin-induced degradation dynamics set the pace for lateral root development. Development 142, 905-909. doi: 10.1242/dev.117234

Hauer-Jákli, M., and Tränkner, M. (2019). Critical leaf magnesium thresholds and the impact of magnesium on plant growth and photo-oxidative defense: a systematic review and meta-analysis from 70 years of research. Front. Plant Sci. 10:766. doi: $10.3389 /$ fpls.2019.00766

Hermans, C., and Verbruggen, N. (2005). Physiological characterization of $\mathrm{Mg}$ deficiency in Arabidopsis thaliana. J. Exp. Bot. 56, 2153-2161. doi: 10.1093/jxb/ eri215
Hermans, C., Vuylsteke, M., Coppens, F., Cristescu, S. M., Harren, F. J. M., Inzé, D., et al. (2010). Systems analysis of the responses to long-term magnesium deficiency and restoration in Arabidopsis thaliana. New Phytol. 187, 132-144. doi: 10.1111/j.1469-8137.2010.03257.x

Hu, Y., Omary, M., Hu, Y., Doron, O., Hoermayer, L., Chen, Q., et al. (2021). Cell kinetics of auxin transport and activity in Arabidopsis root growth and skewing. Nat. Commun. 12:1657. doi: 10.1038/s41467-021-2 1802-3

Ishfaq, M., Wakeel, A., Shahzad, M. N., Kiran, A., and Li, X. (2021). Severity of zinc and iron malnutrition linked to low intake through a staple crop: a case study in east-central Pakistan. Environ. Geochem. Health 43, 4219-4233. doi: 10.1007/s10653-021-00912-3

Israeli, A., Reed, J. W., and Ori, N. (2020). Genetic dissection of the auxin response network. Nat. Plants 6, 1082-1090. doi: 10.1038/s41477-020-0739-7

Koch, M., Busse, M., Naumann, M., Jákli, B., Smit, I., Cakmak, I., et al. (2019). Differential effects of varied potassium and magnesium nutrition on production and partitioning of photoassimilates in potato plants. Physiol. Plant. 166, 921-935. doi: 10.1111/ppl.12846

Koch, M., Winkelmann, M. K., Hasler, M., Pawelzik, E., and Naumann, M. (2020). Root growth in light of changing magnesium distribution and transport between source and sink tissues in potato (Solanum tuberosum L.). Sci. Rep. 10:15192. doi: 10.1038/s41598-020-72313-y

Lakehal, A., and Bellini, C. (2019). Control of adventitious root formation: insights into synergistic and antagonistic hormonal interactions. Physiol. Plant. 165, 90-100. doi: $10.1111 /$ ppl.12823

Lavenus, J., Goh, T., Roberts, I., Guyomarc'h, S., Lucas, M., De Smet, I., et al. (2013). Lateral root development in Arabidopsis: fifty shades of auxin. Trends Plant Sci. 18, 455-463. doi: 10.1016/j.tplants.2013.04.006

Lee, H. W., Cho, C., Pandey, S. K., Park, Y., Kim, M. J., and Kim, J. (2019). LBD16 and LBD18 acting downstream of ARF7 and ARF19 are involved in adventitious root formation in Arabidopsis. BMC Plant Biol. 19:46. doi: 10.1186/s12870-0191659-4

Lenz, H., Dombinov, V., Dreistein, J., Reinhard, M. R., Gebert, M., and Knoop, V. (2013). Magnesium deficiency phenotypes upon multiple knockout of Arabidopsis thaliana MRS2 clade B genes can be ameliorated by concomitantly reduced calcium supply. Plant Cell Physiol. 54, 1118-1131. doi: 10.1093/pcp/ pct062

Li, D., Ma, W., Wei, J., Mao, Y., Peng, Z., Zhang, J., et al. (2020). Magnesium promotes root growth and increases aluminum tolerance via modulation of nitric oxide production in Arabidopsis. Plant Soil 457, 83-95. doi: 10.1007/ s11104-019-04274-9

Li, H., Du, H., Huang, K., Chen, X., Liu, T., Gao, S., et al. (2016). Identification, and functional and expression analyses of the CorA/MRS2/MGT-type magnesium transporter family in maize. Plant Cell Physiol. 57, 1153-1168. doi: 10.1093/pcp/ pcw064

Li, J., Yokosho, K., Liu, S., Cao, H. R., Yamaji, N., Zhu, X. G., et al. (2020). Diel magnesium fluctuations in chloroplasts contribute to photosynthesis in rice. Nat. Plants 6, 848-859. doi: 10.1038/s41477-0200686-3

Li, L., Tutone, A. F., Drummond, R. S. M., Gardner, R. C., and Luan, S. (2001). A novel family of magnesium transport genes in Arabidopsis. Plant Cell 13, 2761-2775. doi: 10.1105/tpc.13.12.2761

Liu, M., Zhang, H., Fang, X., Zhang, Y., and Jin, C. (2018). Auxin acts downstream of ethylene and nitric oxide to regulate magnesium deficiency-induced root hair development in Arabidopsis thaliana. Plant Cell Physiol. 59, 1452-1465. doi: 10.1093/pcp/pcy078

Liu, S., Zhang, Y., Feng, Q., Qin, L., Pan, C., Lamin-Samu, A. T., et al. (2018). Tomato AUXIN RESPONSE FACTOR 5 regulates fruit set and development via the mediation of auxin and gibberellin signaling. Sci. Rep. 8:2971. doi: 10.1038/s41598-018-21315-y

Livak, K. J., and Schmittgen, T. D. (2001). Analysis of relative gene expression data using real-time quantitative PCR and the $2^{-\triangle \Delta C T}$ method. Methods 25, 402-408. doi: 10.1006/meth.2001.1262

Lv, B., Yu, Q., Liu, J., Wen, X., Yan, Z., Hu, K., et al. (2020). Non-canonical AUX/IAA protein IAA33 competes with canonical AUX/IAA repressor IAA5 to negatively regulate auxin signaling. $Е M B O J .39$, e101515. doi: $10.15252 / \mathrm{embj}$. 2019101515 
Ma, C. L., Qi, Y. P., Liang, W. W., Yang, L. T., Lu, Y. B., Guo, P., et al. (2016). MicroRNA regulatory mechanisms on citrus sinensis leaves to magnesium-deficiency. Front. Plant Sci. 7:201. doi: 10.3389/fpls.2016. 00201

Ma, T. L., Wu, W. H., and Wang, Y. (2012). Transcriptome analysis of rice root responses to potassium deficiency. BMC Plant Biol. 12:13. doi: 10.1186/14712229-12-161

Ma, W., Li, J., Qu, B., He, X., Zhao, X., Li, B., et al. (2014). Auxin biosynthetic gene TAR2 is involved in low nitrogen-mediated reprogramming of root architecture in Arabidopsis. Plant J. 78, 70-79. doi: 10.1111/tpj.12448

Maghiaoui, A., Bouguyon, E., Cuesta, C., Section, F. P. W., Alcon, C., Krouk, G., et al. (2020). The Arabidopsis NRT1.1 transceptor coordinately controls auxin biosynthesis and transport to regulate root branching in response to nitrate. J. Exp. Bot. 71, 4480-4494. doi: 10.1093/jxb/ eraa 242

Mao, D., Chen, J., Tian, L., Liu, Z., Yang, L., Tang, R., et al. (2014). Arabidopsis transporter MGT6 mediates magnesium uptake and is required for growth under magnesium limitation. Plant Cell 26, 2234-2248. doi: 10.1105/tpc.114. 124628

Marhavy, P., Vanstraelen, M., De Rybel, B., Ding, Z., Bennett, M. J., Beeckman, T., et al. (2013). Auxin reflux between the endodermis and pericycle promotes lateral root initiation. EMBO J. 32, 149-158. doi: 10.1038/emboj.2012.303

Marschner, H. (2012). Marschner's Mineral Nutrition of Higher Plants, Vol. 89. Cambridge, MA: Academic press.

Mashiguchi, K., Tanaka, K., Sakai, T., Sugawara, S., Kawaide, H., Natsume, M., et al. (2011). The main auxin biosynthesis pathway in Arabidopsis. Proc. Nat. Acad. Sci. U.S.A. 108, 18512-18517. doi: 10.1073/pnas.11084 34108

Meier, M., Liu, Y., Lay-Pruitt, K. S., Takahashi, H., and von Wiren, N. (2020). Auxin-mediated root branching is determined by the form of available nitrogen. Nat. Plants 6, 1136-1145. doi: 10.1038/s41477-020-0 0756-2

Mironova, V., Teale, W., Shahriari, M., Dawson, J., and Palme, K. (2017). The systems biology of auxin in development emoryos. Trends Plant Sci. 22, 225235. doi: 10.1016/j.tplants.2016.11.010

Moret, B., Marhava, P., Fandino, A. C. A., Hardtke, C. S., and ten Tusscher, K. H. W. (2020). Local auxin competition explains fragmented differentiation patterns. Nat. Commun. 11:2965. doi: 10.1038/s41467-020-16 803-7

Nadeem, F., Ahmad, Z., Ul Hassan, M., Ruifeng, W., Diao, X., and Li, X. (2020). Adaptation of foxtail millet (Setaria italica L.) to abiotic stresses: a special perspective of responses to nitrogen and phosphate limitations. Front. Plant Sci. 11:187. doi: 10.3389/fpls.2020.00187

Neuhaus, C., Geilfus, C. M., and Muehling, K. H. (2014). Increasing root and leaf growth and yield in Mg-deficient faba beans (Vicia faba) by $\mathrm{MgSO}_{4}$ foliar fertilization. J. Plant Nutr. Soil Sci. 177, 741-747. doi: 10.1002/jpln.201300127

Nicholas, K. B. (1997). GeneDoc: analysis and visualization of genetic variation. EMB News 4:14.

Niu, Y., Chai, R., Liu, L., Jin, G., Liu, M., Tang, C., et al. (2014). Magnesium availability regulates the development of root hairs in Arabidopsis thaliana (L.) Heynh. Plant Cell Environ. 37, 2795-2813. doi: 10.1111/pce.12362

Niu, Y., Jin, G., Li, X., Tang, C., Zhang, Y., Liang, Y., et al. (2015). Phosphorus and magnesium interactively modulate the elongation and directional growth of primary roots in Arabidopsis thaliana (L.) Heynh. J. Exp. Bot. 66, 3841-3854. doi: 10.1093/jxb/erv181

Novak, O., Henykova, E., Sairanen, I., Kowalczyk, M., Pospisil, T., and Ljung, K. (2012). Tissue-specific profiling of the Arabidopsis thaliana auxin metabolome. Plant J. 72, 523-536. doi: 10.1111/j.1365-313X.2012.05085.x

Oda, K., Kamiya, T., Shikanai, Y., Shigenobu, S., Yamaguchi, K., and Fujiwara, T. (2016). The Arabidopsis mg transporter, MRS2-4, is essential for $\mathrm{mg}$ homeostasis under both low and high mg conditions. Plant Cell Physiol. 57, 754-763. doi: $10.1093 / \mathrm{pcp} / \mathrm{pcv} 196$

Ogura, T., Kobayashi, N. I., Suzuki, H., Iwata, R., Nakanishi, T. M., and Tanoi, K. (2018). Magnesium uptake characteristics in Arabidopsis revealed by Mg-28 tracer studies. Planta 248, 745-750. doi: 10.1007/s00425-0182936-4
Olatunji, D., Geelen, D., and Verstraeten, I. (2017). Control of endogenous auxin levels in plant root development. Int. J. Mol. Sci. 18:2587. doi: 10.3390/ ijms18122587

Paponov, I. A., Teale, W. D., Trebar, M., Blilou, K., and Palme, K. (2005). The PIN auxin efflux facilitators: evolutionary and functional perspectives. Trends Plant Sci. 10, 170-177. doi: 10.1016/j.tplants.2005.02.009

Porco, S., Larrieu, A., Du, Y., Gaudinier, A., Goh, T., Swarup, K., et al. (2016). Lateral root emergence in Arabidopsis is dependent on transcription factor LBD29 regulation of auxin influx carrier LAX3. Development 143, 3340-3349. doi: 10.1242/dev.136283

Roosjen, M., Paque, S., and Weijers, D. (2018). Auxin response factors: output control in auxin biology. J. Exp. Bot. 69, 179-188. doi: 10.1093/jxb/erx237

Saito, T., Kobayashi, N. I., Tanoi, K., Iwata, N., Suzuki, H., Iwata, R., et al. (2013). Expression and functional analysis of the CorA-MRS2-ALR-type magnesium transporter family in rice. Plant Cell Physiol. 54, 1673-1683. doi: 10.1093/pcp/ pct112

Samal, D., Kovar, J. L., Steingrobe, B., Sadana, U. S., Bhadoria, P. S., and Claassen, N. (2010). Potassium uptake efficiency and dynamics in the rhizosphere of maize (Zea mays L.), wheat (Triticum aestivum L.), and sugar beet (Beta vulgaris L.) evaluated with a mechanistic model. Plant Soil 332, 105-121. doi: 10.1007/ s11104-009-0277-6

Sauer, M., and Kleine-Vehn, J. (2019). PIN-FORMED and PIN-LIKES auxin transport facilitators. Development 146:dev168088. doi: 10.1242/dev.168088

Song, Y., Zhou, L., Yang, S., Wang, C., Zhang, T., and Wang, J. (2017). Dosedependent sensitivity of Arabidopsis thaliana seedling root to copper is regulated by auxin homeostasis. Environ. Exp. Bot. 139, 23-30. doi: 10.1016/ j.envexpbot.2017.04.003

Stoeckle, D., Thellmann, M., and Vermeer, J. E. M. (2018). Breakout-lateral root emergence in Arabidopsis thaliana. Curr. Opin. Plant Biol. 41, 67-72. doi: 10. 1016/j.pbi.2017.09.005

Sun, X., Chen, H., Wang, P., Chen, F., Yuan, L., and Mi, G. (2020). Low nitrogen induces root elongation via auxin-induced acid growth and auxin-regulated target of rapamycin (TOR) pathway in maize. J. Plant Physiol. 254:153281. doi: 10.1016/j.jplph.2020.153281

Verbruggen, N., and Hermans, C. (2013). Physiological and molecular responses to magnesium nutritional imbalance in plants. Plant Soil 368, 87-99. doi: 10.1007/ s11104-013-1589-0

Vosolsobe, S., Skokan, R., and Petrasek, J. (2020). The evolutionary origins of auxin transport: what we know and what we need to know. J. Exp. Bot. 71, 3287-3295. doi: $10.1093 / \mathrm{jxb} / \mathrm{eraa} 169$

Wang, J., Moeen-ud-din, M., and Yang, S. (2021). Dose-dependent responses of Arabidopsis thaliana to zinc are mediated by auxin homeostasis and transport. Environ. Exp. Bot. 189:104554. doi: 10.1016/j.envexpbot.2021. 104554

Wang, R., and Estelle, M. (2014). Diversity and specificity: auxin perception and signaling through the TIR1/AFB pathway. Curr. Opin. Plant Biol. 21, 51-58. doi: 10.1016/j.pbi.2014.06.006

Wang, Z., Ul Hassan, M., Nadeem, F., Wu, L., Zhang, F., and Li, X. (2020). Magnesium fertilization improves crop yield in most production systems: a meta-analysis. Front. Plant Sci. 10:1727. doi: 10.3389/fpls.2019.01727

Weijers, D., and Wagner, D. (2016). Transcriptional responses to the auxin hormone, in: Merchant, S.S. (Ed.). Annu. Rev. Plant Biol. 67, 539-574. doi: 10.1146/annurev-arplant-043015-112122

Weiler, E. W., Jourdan, P. S., and Conrad, W. (1981). Use of immunoassay in plant-science. Levels of indole-3-acetic-acid in intact and decapitated coleoptiles as determined by a specific and highly sensitive solidphase enzyme-immunoassay. Planta 153, 561-571. doi: 10.1007/bf00 385542

Yan, Y. W., Mao, D. D., Yang, L., Qi, J. L., Zhang, X. X., Tang, Q. L., et al. (2018). Magnesium transporter MGT6 plays an essential role in maintaining magnesium homeostasis and regulating high magnesium tolerance in Arabidopsis. Front. Plant Sci. 9:274. doi: 10.3389/fpls.2018. 00274

Yang, L.-T., Zhou, Y.-F., Wang, Y.-Y., Wu, Y.-M., Ye, X., Guo, J.-X., et al. (2019). Magnesium deficiency induced global transcriptome change in Citrus sinensis leaves revealed by RNA-Seq. Int. J. Mol. Sci. 20, 3129. doi: 10.3390/ijms20133129 
Zhang, L., Wen, A., Wu, X., Pan, X., Wu, N., Chen, X., et al. (2019a). Molecular identification of the magnesium transport gene family in Brassica napus. Plant Physiol. Biochem. 136, 204-214. doi: 10.1016/j.plaphy.2019.01.017

Zhang, L., Peng, Y., Li, J., Tian, X., and Chen, Z. (2019b). OsMGT1 confers resistance to magnesium deficiency by enhancing the import of $\mathrm{mg}$ in rice. Int. J. Mol. Sci. 20:207. doi: 10.3390/ijms20010207

Zhang, P., Sun, L., Qin, J., Wan, J., Wang, R., and Li, S. (2018). cGMP is involved in $\mathrm{Zn}$ tolerance through the modulation of auxin redistribution in root tips. Environ. Exp. Bot. 147, 22-30. doi: 10.1016/j.envexpbot.2017.10.025

Zhang, Y., Hartinger, C., Wang, X., and Friml, J. (2020). Directional auxin fluxes in plants by intramolecular domain-domain coevolution of PIN auxin transporters. New Phytol. 227, 1406-1416. doi: 10.1111/nph.16629

Zhang, Z., Liu, D., Meng, H., Li, S., Wang, S., Xiao, Z., et al. (2020). Magnesium alleviates aluminum toxicity by promoting polar auxin transport and distribution and root alkalization in the root apex in populus. Plant Soil 448, 565-585. doi: 10.1007/s11104-020-04459-7
Conflict of Interest: The authors declare that the research was conducted in the absence of any commercial or financial relationships that could be construed as a potential conflict of interest.

Publisher's Note: All claims expressed in this article are solely those of the authors and do not necessarily represent those of their affiliated organizations, or those of the publisher, the editors and the reviewers. Any product that may be evaluated in this article, or claim that may be made by its manufacturer, is not guaranteed or endorsed by the publisher.

Copyright $\odot 2021$ Ishfaq, Zhong, Wang and Li. This is an open-access article distributed under the terms of the Creative Commons Attribution License (CC BY). The use, distribution or reproduction in other forums is permitted, provided the original author(s) and the copyright owner(s) are credited and that the original publication in this journal is cited, in accordance with accepted academic practice. No use, distribution or reproduction is permitted which does not comply with these terms. 